\title{
SUPPLIER SELECTION IN TELECOM SUPPLY CHAIN MANAGEMENT: A FUZZY-RASCH BASED COPRAS-G METHOD
}

\author{
Kajal CHATTERJEE ${ }^{*}$ Samarjit KAR \\ Department of Mathematics, National Institute of Technology, Durgapur-713 209, WB, India
}

Received 10 May 2016; accepted 11 February 2017

\begin{abstract}
In the past decade, global competition are forcing firms to increase their level of outsourcing for raw or semi-finished products and building long term relationship with their supply chain partners. The objective is to present a wide-ranging decision making technique for ranking supplier alternatives in view of the effect of selected criteria. A proposed method is developed aiming the usage of Fuzzy-Rasch model applying five point Likert scale for criteria weight and Grey based COmplex PRoportional ASsessment (COPRAS-G) method for evaluating and ranking the potential alternatives, as per criteria. The applicability of the induced methodology for supplier selection problem in all environments is shown through a case study in telecommunication sector. A sensitivity analysis is performed based on changing weight patterns of criteria to show the stability in ranking result of the proposed approach. Further, a comparative analysis between the ranking results of proposed method done with existing grey multi-attribute decision-making methods viz. VIKOR-G, ARAS-G and TOPSIS-G using spearman's correlation coefficient for checking the reliability of the ranking result.
\end{abstract}

Keywords: multi criteria decision making, supplier selection, fuzzy sets, Rasch model, COPRAS-G.

JEL Classification: D79, D81, J23, K22, L63.

\section{Introduction}

In contemporary years, under constant pressure to deliver high-quality products at reduced rate in short time, companies are opting for outsourcing their operations to utilize global resources more efficiently (Reza et al. 2008). Since parts from suppliers in supply chain determine the superiority of completed products by producers, evaluation of supplier's performance is a challenge to the manufacturer and purchasing managers (Li et al. 2009).

With the globalization and the emergence of interdependent organizations, there has been a steady increase in the outsourcing of parts and services from reputed firms to compete through their supply chain (Onut et al. 2009). However in global scenario, the main

*Corresponding author. E-mail: kajalchatterjee19@yahoo.in

This is an Open Access article distributed under the terms of the Creative Commons Attribution License (http://creativecommons. org/licenses/by/4.0/), which permits unrestricted use, distribution, and reproduction in any medium, provided the original author and source are credited. 
barrier in selecting suitable alternative supplier involve political, economic and social related risk factors that need to identified and proper methodology be develop to deal with them (Viswanadham, Samvedi 2013). Up to now, several supplier selection decision framework are proposed to evaluate the potential supply chain partners in many industries, but very few works are done in telecom supply chain considering various impacts of risk factors that influence overall business performance (Badri Ahmadi et al. 2016). The nature of supplier selection processes is generally complex, especially when the company has a multi-supply chain involving large variety of products and vendors.

The aim of this research is to demonstrate how a multiple criteria decision-making (MCDM) approach can be effectively applied for the supplier selection process in a risk based supply chain. MCDM structure information and evaluate decision problems with conflicting criteria. Prioritizing suitable alternatives and criteria's rely on expert's subjective decisions for appropriate choice (Felice et al. 2015). Traditionally, decision makers (DMs') judgment in MCDM problems being in crisp mode, fuzzy logic is introduced to handle imprecise information. Suppliers evaluation based on various methods involving fuzzy methodology is very comprehensive viz. fuzzy entropy-VIKOR (Shemshadi et al. 2011), fuzzy DEMATELANP-TOPSIS (Buyukozkan, Cifci 2012) fuzzy TOPSIS (Roshandel et al. 2013), type-2 fuzzy soft TOPSIS (Chatterjee, Kar 2013a), Interval type-2 fuzzy COPRAS (Keshavarz Ghorabaee et al. 2014), ranking interval type-2 fuzzy set (Kar, Chatterjee 2014), AHP-Entropy-TOPSIS framework (Freeman, Chen 2015), ISM based fuzzy AHP-TOPSIS method (Beikkhakhian et al. 2015), rule based fuzzy inference system (Paul 2015), interval-valued fuzzy TOPSIS (Chatterjee, Kar 2016), fuzzy EDAS (Keshavarz Ghorabaee et al. 2016a). Grey theory can flexibly handle vague information in comparison to fuzzy counterpart (Oztaysi 2014). In recent years, the grey-based approach are applied to deal with supplier selection problem under uncertainty viz. grey based compromise ranking (Chatterjee, P., Chatterjee, R. 2012), AHP based CORPAS-G (Hashemkhani Zolfani et al. 2012), grey-analytical network process (Dou et al. 2014), Grey AHP based TOPSIS (Oztaysi 2014), ANP based Grey relational analysis (Hashemi et al. 2015).

Hybridization of fuzzy and grey interval set are also done on MCDM related supplier selection problem, viz. fuzzy AHP based grey relational analysis (Golmohammadi, Parast 2012), fuzzy ANP based COPRAS-G (Tavana et al. 2013; Nguyen et al. 2014), fuzzy AHP based CORPAS-G (Aghdaie et al. 2013a). In the current study, we propose a new hybrid decision model for the supplier selection based on the fuzzy-Rasch model (Huang, Peng 2012; Chatterjee, Kar 2013b) for assessing risk attributes weight and COPRAS-G method (Zavadskas et al. 2008) for ranking of alternative suppliers.

Recently, companies are investigating on various risk based supply chain factors in selection of optimal supplier alternatives (Paul 2015; Meena, Sarmah 2016). The proposed methodology is applied to resolve the supplier selection problem in telecommunication sector within Indian perspective. Few works has been done in analysis of telecommunication supply chain taking Indian telecom sector as a case study (Pramod et al. 2016). Fuzzy logic is integrated with Rasch model due to inefficiency of Rasch model to handle the inexact qualitative factors of the expert judgments. The COPRAS-G method rank supplier alternatives in terms of their significance and utility degree by interval based grey relational grade. To show 
the stability of the ranking results of the alternatives, a sensitivity analysis is performed by changing the weights of the criteria. For checking the validity and reliability of fuzzy Rasch based COPRAS-G MCDM model in evaluating alternatives, the obtained ranking result is compared with results obtained by some existing methods in grey intervals such as Technique for Order Preference by Similarity to Ideal Solution (TOPSIS) (Oztaysi 2014), Additive Ratio Assessment (ARAS) (Turskis, Zavadskas 2010), Vlse Kriterijumska Optimizacija Kompromisno Resenje (VIKOR) (Chatterjee, P., Chatterjee, R. 2012).

To help meet these objectives, the rest of the paper organized as follows. In Section 1, we provide an overview of fuzzy number and grey number along with brief description of fuzzy Rasch and COPRAS-G model. Section 2 presents the proposed hybrid model to deal with MCDM problems along with the flow chart. Application of the proposed methodology is given in Section 3, along with the criteria descriptions. Section 4 shows the computational steps of the method, followed by the result discussion in Section 5 . The last section provides concluding remarks.

\section{Preliminaries}

In this section, we present some basics on fuzzy number, grey number and its related methods.

\subsection{Fuzzy numbers}

A fuzzy number is a special fuzzy set $\tilde{M}=\left\{\left(x, \mu_{\tilde{M}}(x)\right), x \in R\right\}$, where $x$ takes its values on real line $R(-\infty \leq x \leq \infty)$ and $\mu_{\tilde{M}}(x)$ being a convex fuzzy subset maps continuously from $R$ to $[0,1]$ (Aghdaie et al. 2013a). A triangular fuzzy number (TFN), (Fig. 1), denoted as triplet $\tilde{N}=(a, b, c)$ where $a \leq b \leq c$, express the relative strength of each pair of elements in same hierarchy with membership function $\mu_{\tilde{N}}(x)$ defined as follows:

$$
\mu_{\tilde{N}}(x)=\left\{\begin{array}{cl}
0 & x \leq a \\
(x-a) /(b-a) & a \leq x \leq b, \\
(c-x) /(c-b) & b \leq x \leq c, \\
0 & x \geq c .
\end{array}\right.
$$

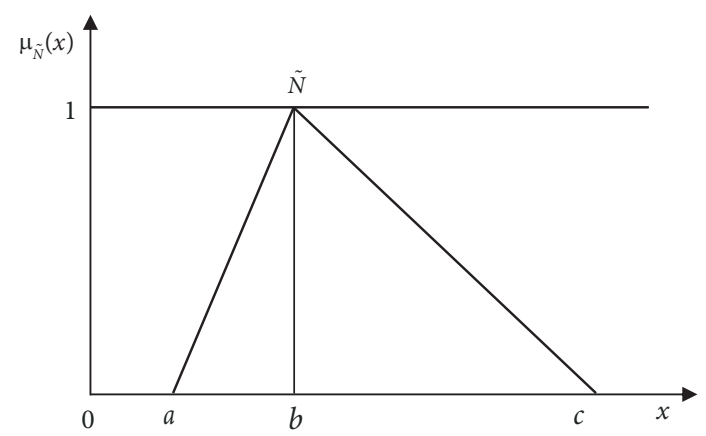

Figure 1. Triangular fuzzy number $(\mathrm{TFN}) \tilde{N}=(a, b, c)$ (source: Buyukozkan, Cifci 2012) 
Using extension principle, the arithmetic operations of TFNs expressed as per Onut et al. (2009). The concept of linguistic variable is very useful in dealing with situation too complex or ill- defined (Mehrjerdi 2014). Since linguistic variables are not arithmetically operable, relating it with uncertain numbers like fuzzy or grey depict significance of every standard verbal term. In this decision-making problem, important weight of criteria and alternative ranking are represented by linguistic variables in TFNs based Likert scale (Huang, Peng 2012) and grey interval number scale (Hashemi et al. 2015) respectively.

\subsection{Grey number}

Grey theory, proposed by Deng (1998) includes fuzziness, as it can flexibly integrate uncertainty and incomplete information into the evaluation process. Its major advantage is the ability to create acceptable outcomes using a comparatively small data or when there is changeability in factors (Chen, Tzeng 2004). Due to presence of imprecise information and uncertain relation in real world problems, extending the applications from white numbers (crisp values) to grey numbers is a necessary task. Alternative's selection can be viewed as a grey system process and grey theory may be applied to resolve it (Zavadskas et al. 2009a). The ratings of alternatives against criteria in decision-making process are described by linguistic variables and can be expressed in grey numbers. The concepts of grey-based system, set and number along with notation are described in Mehrjerdi (2014). A grey system comprises of uncertain data in grey numbers and variables, shown in Figure 2.

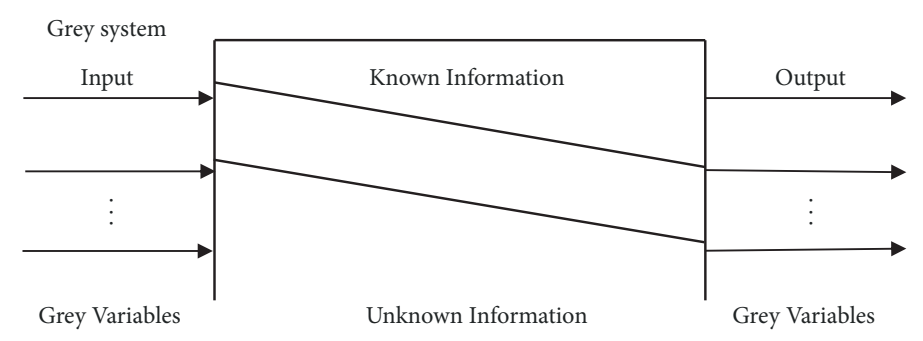

Figure 2. The concept of Grey System (source: Deng 1998)

The grey number $(\otimes G)$ is a number with uncertain and incomplete information with attributes grades categorised by linguistic variables in numerical intervals (Zavadskas et al. 2009b). The upper and lower limits of $G$ can be estimated and defined in grey interval $\otimes G=[\underline{G}, \bar{G}]$. The operations of grey numbers defined on a set of intervals are described in Zhang et al. (2005).

\subsection{Fuzzy Rasch model}

As per Belevdere, Morton (2010), Rasch model, well-known as One-Parameter Logistic Model (1PL), imitate both exertion of item and individual ability while converting raw data from a "rating scale to an equal interval scale" measuring in logits (log odd units). Since the development of Rasch model, it has been used for evaluating the values of item and person 
parameters shown below (Ho et al. 2016). Rasch model combined with Fuzzy Logic model of Perception (FLMP) gives far better result than those of fuzzy logic and utilizing fuzzy theory to score psychological measurement seems feasible. Till now, scaling and membership generating of previous works using fuzzy set theory (FST) to psychological measurement are based on classical test theory (CTT) rather than modern test theory, also called item response theory (IRT) (Yu, Wu 2009). Since its development, the Rasch model is being used for assessing the values of item and person parameters, as shown in Eq. (1) (Peng et al. 2013):

$$
\log \left(\frac{P_{n i j}}{P_{n i(j-1)}}\right)=\theta_{n}-\left(\delta_{i}+\tau_{j}\right) .
$$

In Eq. (1), $P_{n i j}$ and $P_{n i(j-1)}$ represent the probability that item $n$ obtains scores $j$ and $(j-$ 1) respectively from expert $i . \theta_{n}$ represent the measure score (item difficulty) of the item $n$, $\delta_{i}$ represent the measure score (individual difficulty) of the expert $i$ and $\tau_{j}$ represent the step difficulty (threshold difficulty) of category $j$.

The rating scale model is useful if psychological distances between categories are identical as in case of Likert scale for all items, i.e.

$$
\delta_{i j}=\delta_{i}+\tau_{j} ; i=1,2, \ldots, E ; j=i, 2, \ldots, m .
$$

In Eq. (2), $E$ represents the number of experts; $m$ represents the number of linguistic scales, ranging from 'very unimportant' to 'very important' while $\delta_{i j}$ represents overall measured score of expert $i$ for category $j$ (Peng et al. 2013). In the past decade, different algorithms proposed to various models with different results and until now, scaling and membership generating using fuzzy set theory (FST) to psychological measurement based on classical test theory (CTT) rather than modern item response theory (IRT). Rasch model is a feasible method of generating grey numbers of importance scores obtained using the Likert rating scale.

- Yu, Wu (2009) proposed a fuzzy item response model, combining item response theory (IRT) and fuzzy set theory generating membership function to score and predict validity of psychological measurement.

- Huang, Peng (2011) used Rasch model to obtain the weight of grey relational coefficient to analyse the performance of international tourist hotels in seven district of Taiwan.

- Nurnadiah and Lazim (2012) utilized interval type-2 fuzzy set (IT2FS) concept in Rasch model to assess the attribute weight in fuzzy MCDM method based on credibility of data.

- Huang, Peng (2012) applied the fuzzy Rasch model in TOPSIS method to analyse the tourism destination competitiveness (TDC) of nine Asian countries.

- Chatterjee, Kar (2013b) provided a new fuzzy-Rasch VIKOR decision model to choose the most optimal and low risk warehouse spot from a number of potential alternatives where uncertain information are exploited getting group of decision makers as multiple experts providing decisions through TFNs.

- Peng et al. (2013) applied Rasch model in data envelopment analysis (DEA) to analyse the performance of international tourist hotels located at seven district of Taiwan.

- Ho et al. (2016) constructed a learning outcome assessment tool to analyse curriculum and learning outcomes based on Rasch GSP curve, GSM (Grey Structural Modelling) and MSM (Matrix Based Structure Modelling). 


\subsection{COPRAS-G method}

The MCDM method, COPRAS (COmplex PropoRtional Assessment) of alternatives, proposed by Zavadskas et al. (1994), assumes comparative dependency of the significance, and utility degree on a system of criteria for describing alternatives and weights of the attributes. However, it fails to deal with uncertain situation, lack of information and conflict resolution among experts and cannot express ambiguous values around a given discrete value (Zavadskas et al. 2009b). Although, some fuzzy methods would resolve the shortcomings of non-fuzzy methods, they suffer from limitations of mapping a membership function. In this situation, Zavadskas et al. (2008) proposed COPRAS based grey relations methodology for defining the utility of an alternative. The method successfully applied linguistic variables with Grey relations for evaluating the alternatives with attributes in grey interval values and effectively handles the problem of dealing with imprecise and subjective data for processing incomplete information, increasing the efficacy level in the decision-making process.

The COPRAS-G method has wide-ranging application for all MCDM problems that need decision making in fuzzy setting. This approach analyses and estimate the different alternatives according to their significance and degree of utility. Other MCDM approaches do not have such features and that is the reason why COPRAS-G succeeded in the decision- making process and researchers are now taking keen note of this area. In recent years, the CORPAS$\mathrm{G}$ method has been applied to solve complex multi-criteria decision-making models, which are listed below:

- Zavadskas et al. (2009a) demonstrate how simulation can be used to reflect fuzzy inputs for choice of contractor with CORPAS-G method on fuzzy based multiple attributes input.

- Hashemkhani Zolfani et al. (2012) utilized a hybrid AHP and COPRAS-G based MCDM model for supplier selection.

- Tavana et al. (2013) proposed the fuzzy Analytic Network Process (ANP) and the COPRAS-G method, in determine the weight of the social media platform selection criteria in a fuzzy environment and select the most suitable social media platform.

- Aghdaie et al. (2013a) presents a novel approach, which integrates fuzzy analytic hierarchy process (FAHP), and COPRAS-G method for market segment evaluation and selection.

- Aghdaie et al. (2013b) proposed hybrid model integrating Step-Wise weight Assessment Ratio Analysis (SWARA) and COPRAS with grey relations and applied for machine tool evaluation and selection.

- Ecer (2014) propose a hybrid model of AHP and COPRAS-G methods for evaluating the website quality of banks in Turkey.

- Liou et al. (2015) proposes a novel hybrid model that addresses dependent relationships between various criteria using DEMATEL and the vague and incomplete information using modified COPRAS-G for improving and selecting suppliers in green supply chain management.

- Pancholi, Bhatt (2016) presents a multi-criteria decision-making approach based on COPRAS-G to overcome the limitations of Failure Mode Effect and Criticality Analysis (FMECA) for aluminium wire process rolling mills. 


\section{The proposed methodology}

In this paper, we propose a new hybrid model integrating fuzzy-Rasch (Huang, Peng 2012; Peng et al. 2013) model to derive attributes weightage and COPRAS-G (Zavadskas et al. 2008; Ecer 2014) using group decision making procedure for handling the multi-criteria decision making $(\mathrm{MCDM})$ procedure in ranking alternatives based on various criteria weights. Group decision-making is an efficient way to deal with conflictive preferences of decision-makers having different background and different level of knowledge about the criteria and alternatives. The following section includes three phases described below for MCDM problem. In addition, the ranking alternatives with COPRAS-G are compared with other MCDM methods in grey intervals and an outline of the above three phase is presented in Figure 3.

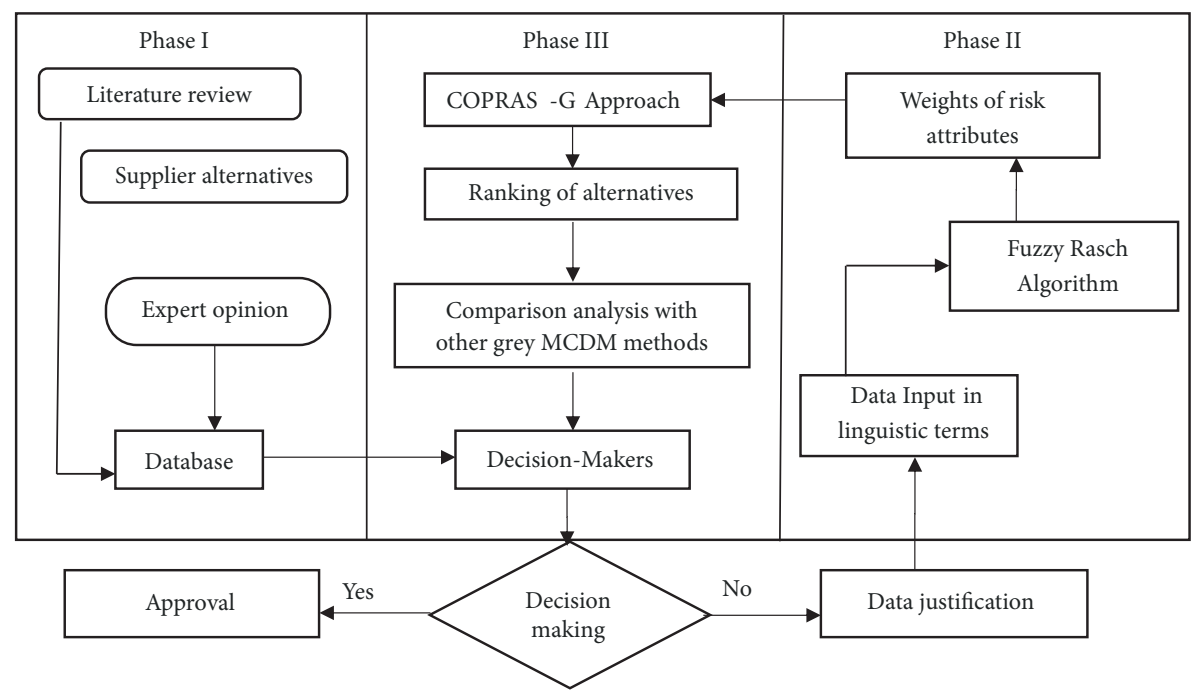

Figure 3. Outline for proposed hybrid model of fuzzy Rasch and COPRAS-G for decision making

\section{Phase I: Expert opinions in decision making}

Step 1: A team of expert decision maker's outlines the alternatives from data bank collected from various sources and determines the evaluation criteria based on optimal performance.

\section{Phase II: Fuzzy Rasch method for criteria weight}

Step 2: In this section, we summarize the process of obtaining the weights of criteria. First, the feedback among the selected experts (in questionnaire form) are identified for calculating the degree of importance of each criteria, using 5-point Likert rating scale (from 1- very low to 5 - very high).

Step 3: Using Rasch model, step parameters $\left(\delta_{i j}\right)$ are computed to determine the fuzzy weight $\bar{W}_{i j}=\left(\delta_{i j}^{L}, \delta_{i j}^{M}, \delta_{i j}^{U}\right)$ of each decision-making expert $i(i=1,2, \ldots, E)$ for step-parameter 
$j(i=1,2, \ldots, h)$. Putting $h=5$, the TFNs weights of 5-point Likert scale values are as follows: very low $\bar{W}_{i 1}=\left(\delta_{i 1}^{L}, \delta_{i 1}^{M}, \delta_{i 1}^{U}\right)$; medium low $\bar{W}_{i 2}=\left(\delta_{i 2}^{L}, \delta_{i 2}^{M}, \delta_{i 2}^{U}\right)$; medium $\bar{W}_{i 3}=\left(\delta_{i 3}^{L}, \delta_{i 3}^{M}, \delta_{i 3}^{U}\right)$; Medium high $\bar{W}_{i 4}=\left(\delta_{i 4}^{L}, \delta_{i 4}^{M}, \delta_{i 4}^{U}\right)$; very high $\bar{W}_{i 5}=\left(\delta_{i 5}^{L}, \delta_{i 5}^{M}, \delta_{i 5}^{U}\right)$.

Step 4: The calculated triangular fuzzy weight $\bar{W}_{i j k}=\left(\delta_{i j k}^{L}, \delta_{i j k}^{M}, \delta_{i j k}^{U}\right)$ for $n$ criteria $C_{k}(k=1$, $2, \ldots, n)$ is used as a standby for the original degree of importance (Step 2) considered above and arithmetic average method is incorporated to integrate the fuzzy weight of each expert $i(i=1,2, \ldots, E)$ as in Eq. (3) as follows:

$$
\bar{W}_{k}=\frac{1}{E}\left[\sum_{i=1}^{E} \bar{W}_{i j k}\right]=\left(\delta_{k}^{L}, \delta_{k}^{M}, \delta_{k}^{U}\right) .
$$

Step 5: Using Eq. (4), the weights of each criteria in Eq. (3) are further defuzzified by calculating the best Non-fuzzy performance $\left(B N P_{k}\right)$ value for $(k=1,2, \ldots, n)$ and following Eq. (5), the standardise weight $W_{k}(k=1,2, \ldots, n)$ are evaluated, to be used in ranking the alternatives.

$$
\begin{gathered}
B N P_{k}=\frac{\left[\left(\delta_{k}^{U}-\delta_{k}^{L}\right)+\left(\delta_{k}^{M}-\delta_{k}^{L}\right)\right]}{3}+\delta_{k}^{L} \quad \forall k=1,2, \ldots, n ; \\
W_{k}=S B N P_{k}=\frac{B N P_{k}}{\sum_{k=1}^{n} B N P_{k}} \text { where } \sum_{k=1}^{n} S B N P_{k}=1, \quad 0 \leq W_{k} \leq 1 .
\end{gathered}
$$

\section{Phase III: COPRAS-G method for ranking alternatives}

Assume a decision-making problem, containing $m$ alternatives $A_{i}(i=1,2, \ldots, m)$ and $n$ criteria $C_{j}(j=1,2, \ldots, n)$ for evaluating the alternatives for $E$ experts $D M_{p}(p=1,2, \ldots, E)$ in decision-making process. Also, suppose that $W_{j}(j=1,2, \ldots, n)$ denotes the weight of criteria $C_{j}(j=1,2, \ldots, n)$ obtained in Phase II. The procedure of applying COPRAS-G method for dealing with MCDM method consists of the following steps, assuming decision makers are of similar importance.

Step 6: First, each expert expresses his or her evaluations regarding the ratings of alternatives on criteria and criteria weights. Suppose that $\otimes x_{i j}^{p}=\left[x_{i j}^{p}, \bar{x}_{i j}^{p}\right] \forall i=1,2, \ldots, m ; j=1,2, \ldots ., n$ is the evaluation of the alternative $A_{i}(i=1,2, \ldots, m)$ rating on criterion $j$ for $p^{\text {th }}$ expert decision maker $D M_{p}(p=1,2, \ldots, E)$. Then, the decision matrix $X^{p}$, in grey interval value $\left[\otimes x_{i j}^{p}\right]$ is constructed as follows:

$$
X^{p}=\left[\otimes x_{i j}^{p}\right]_{m \times n}=\left[\begin{array}{cccc}
{\left[\underline{x}_{11}^{p} ; \bar{x}_{11}^{p}\right]} & {\left[\underline{x}_{12}^{p} ; \bar{x}_{12}^{p}\right]} & \ldots & {\left[\underline{x}_{1 n}^{p} ; \bar{x}_{1 n}^{p}\right]} \\
{\left[\underline{x}_{21}^{p} ; \bar{x}_{21}^{p}\right]} & {\left[\underline{x}_{22}^{p} ; \bar{x}_{22}^{p}\right]} & \ldots & {\left[\underline{x}_{2 n}^{p} ; \bar{x}_{2 n}^{p}\right]} \\
\vdots & \vdots & \ddots & \vdots \\
{\left[\underline{x}_{m 1}^{p} ; \bar{x}_{m 1}^{p}\right]} & {\left[\underline{x}_{m 2}^{p} ; \bar{x}_{m 2}^{p}\right]} & \ldots & {\left[\underline{x}_{m n}^{p} ; \bar{x}_{m n}^{p}\right]}
\end{array}\right],
$$

where $\otimes x_{i j}^{p}$ is determined by $\underline{x}_{i j}^{p}$ (the smallest value) and $\bar{x}_{i j}^{p}$ (the highest value) with $m$ and $n$ the number of alternatives and criteria, respectively. 
Step 7: Construct the average decision matrix $X$, shown as follows:

$$
X=\left[\otimes x_{i j}\right]_{m \times n}=\left[\begin{array}{cccc}
{\left[\underline{x}_{11} ; \bar{x}_{11}\right]} & {\left[\underline{x}_{12} ; \bar{x}_{12}\right]} & \ldots & {\left[\underline{x}_{1 n} ; \bar{x}_{1 n}\right]} \\
{\left[\underline{x}_{21} ; \bar{x}_{21}\right]} & {\left[\underline{x}_{22} ; \bar{x}_{22}\right]} & \ldots & {\left[\underline{x}_{2 n} ; \bar{x}_{2 n}\right]} \\
\vdots & \vdots & \ddots & \vdots \\
{\left[\underline{x}_{m 1} ; \bar{x}_{m 1}\right]} & {\left[\underline{x}_{m 2} ; \bar{x}_{m 2}\right]} & \ldots & {\left[\underline{x}_{m n} ; \bar{x}_{m n}\right]}
\end{array}\right],
$$

where $\otimes x_{i j}=\left[\underline{x}_{i j} ; \bar{x}_{i j}\right], \forall i=1,2, \ldots, m ; j=1,2, \ldots, n$ and

$$
\underline{x}_{i j}=\left(\frac{\underline{x}_{i j}^{1} \oplus \underline{x}_{i j}^{2} \oplus \ldots \oplus \underline{x}_{i j}^{k}}{k}\right) \text { and } \bar{x}_{i j}=\left(\frac{\bar{x}_{i j}^{1} \oplus \bar{x}_{i j}^{2} \oplus \ldots \oplus \bar{x}_{i j}^{k}}{k}\right) \text {. }
$$

Step 8: Calculate the weighted normalized decision matrix:

First normalize the data in the decision- making matrix in Eq. (7) to determine importance weight of the selection criteria, using Eq. (10) below:

$$
\underline{\tilde{x}}_{i j}=\frac{2 \underline{x}_{i j}}{\left[\sum_{i=1}^{m} \underline{x}_{i j}+\sum_{i=1}^{m} \bar{x}_{i j}\right]} ; \quad \tilde{\bar{x}}_{i j}=\frac{2 \bar{x}_{i j}}{\left[\sum_{i=1}^{m} \underline{x}_{i j}+\sum_{i=1}^{m} \bar{x}_{i j}\right]} .
$$

The normalization process result in the following normalized decision matrix $\tilde{X}$ shown in Eq. (11):

$$
\tilde{X}=\left[\otimes \tilde{x}_{i j}\right]_{m \times n}=\left[\begin{array}{cccc}
{\left[\underline{\tilde{x}}_{11} ; \tilde{\bar{x}}_{11}\right]} & {\left[\underline{\tilde{x}}_{12} ; \tilde{\bar{x}}_{12}\right]} & \ldots & {\left[\underline{\tilde{x}}_{1 n} ; \tilde{\bar{x}}_{1 n}\right]} \\
{\left[\underline{\tilde{x}}_{21} ; \overline{\bar{x}}_{21}\right]} & {\left[\underline{\tilde{x}}_{22} ; \overline{\bar{x}}_{22}\right]} & \ldots & {\left[\underline{\tilde{x}}_{2 n} ; \overline{\bar{x}}_{2 n}\right]} \\
\vdots & \vdots & \ddots & \vdots \\
{\left[\underline{\tilde{x}}_{m 1} ; \tilde{\bar{x}}_{m 1}\right]} & {\left[\underline{\tilde{x}}_{m 2} ; \tilde{\bar{x}}_{m 2}\right]} & \ldots & {\left[\underline{\tilde{x}}_{m n} ; \tilde{\bar{x}}_{m n}\right]}
\end{array}\right] .
$$

In order to construct the weighted normalized decision matrix, we first calculate the weighted normalized values as follows:

$$
\underline{\hat{x}}_{i j}=\underline{\tilde{x}}_{i j} \cdot W_{j} \text { and } \hat{\bar{x}}_{i j}=\tilde{\bar{x}}_{i j} . W_{j} \forall i=1,2, \ldots, m ; j=1,2, \ldots, n,
$$

where $W_{j}(j=1,2, \ldots, n)$ is the $j^{\text {th }}$ criterion determined by Eq. (5) of fuzzy Rasch model (Phase II).

We then construct weighted normalized decision support matrix $\hat{X}$ as using Eq. (13) as follows:

$$
\hat{X}=\left[\otimes \hat{x}_{i j}\right]_{m \times n}\left[\begin{array}{cccc}
{\left[\underline{\hat{x}}_{11}, \hat{\bar{x}}_{11}\right]} & {\left[\underline{\hat{x}}_{12}, \hat{\bar{x}}_{12}\right]} & \ldots & {\left[\underline{\hat{x}}_{1 n}, \hat{\bar{x}}_{1 n}\right]} \\
{\left[\underline{\hat{x}}_{21}, \hat{\bar{x}}_{21}\right]} & {\left[\hat{\hat{x}}_{22}, \hat{\bar{x}}_{22}\right]} & \ldots & {\left[\underline{\hat{x}}_{2 n}, \hat{\bar{x}}_{2 n}\right]} \\
\vdots & \vdots & \ddots & \ddots \\
{\left[\underline{\hat{x}}_{m 1}, \hat{\bar{x}}_{m 1}\right]} & {\left[\underline{\hat{x}}_{m 2}, \hat{\bar{x}}_{m 2}\right]} & \ldots & {\left[\underline{\hat{x}}_{m n}, \hat{\bar{x}}_{m n}\right]}
\end{array}\right] .
$$

Step 9: Determine the relative significance of each alternatives

Criterion values sum $\left(P_{i}\right) \forall i=1,2, \ldots, m$ (preferably larger values) and sum $\left(R_{i}\right)$ (preferably smaller values) for each alternative are calculated, where $g(1 \leq g \leq n)$ the number of criteria which must be maximized. 


$$
\begin{gathered}
P_{i}=\frac{1}{2} \sum_{j=1}^{g}\left(\underline{\hat{x}}_{i j}+\hat{\bar{x}}_{i j}\right) ; \\
R_{i}=\frac{1}{2} \sum_{j=g+1}^{n}\left(\underline{\hat{x}}_{i j}+\hat{\bar{x}}_{i j}\right) .
\end{gathered}
$$

Least value of $R_{i}$ is determined as:

$$
R_{\min }=\min _{i} R_{i} \forall i=1,2, \ldots, m .
$$

The relative significance $\left(Q_{i}\right)$ of each alternative is calculated as:

$$
Q_{i}=P_{i}+\frac{R_{\min } \sum_{i=1}^{m} R_{i}}{R_{i} \sum_{i=1}^{m} \frac{R_{\min }}{R_{i}}} .
$$

Step 10: Calculate the utility degree of each alternative.

Optimally criterion $\left(Q_{\max }\right)$ is calculated first for utility degree of each alternative.

$$
Q_{\max }=\max _{i} Q_{i} \forall i=1,2, \ldots, m .
$$

The utility degree $\left(N_{i}\right)$ of each alternative, ranging from $0 \%$ (for worst) to $100 \%$ (for best) is calculated by comparing the alternatives with the best one as:

$$
N_{i}=\left[\frac{Q_{i}}{Q_{\max }}\right] \times 100 \% .
$$

The COPRAS-G methodology assesses the direct and relative dependency of criteria's weight with utility degree of the alternatives. The flow chart for the proposed hybrid model is given in Figure 4.

\section{Application of the suggested approach in Telecom sector}

\subsection{Background of the case study}

This paper select suitable supplier on decision support framework from a given set of potential data. Telecommunication is vital for evolution of tech-driven and dynamic economy. In Indian perspective, this sector has gone through a number of substantial modifications in the past decade due to technical advances and customer demand. To strive with users' demands for better quality products at lower price, this sector need to offer new products and services for which new suppliers selection is a necessary task.

In Indian perspective, the companies' main objective are to create low cost package for long distance calls providing customer assistance support line ensuring online monthly phone calls details. For this, the company needs to make new investments in buying new communication equipment's from suppliers for getting a competitive edge in the market. The following section describes a hierarchy of criteria, alternatives and goal for evaluating supplier alternatives. 


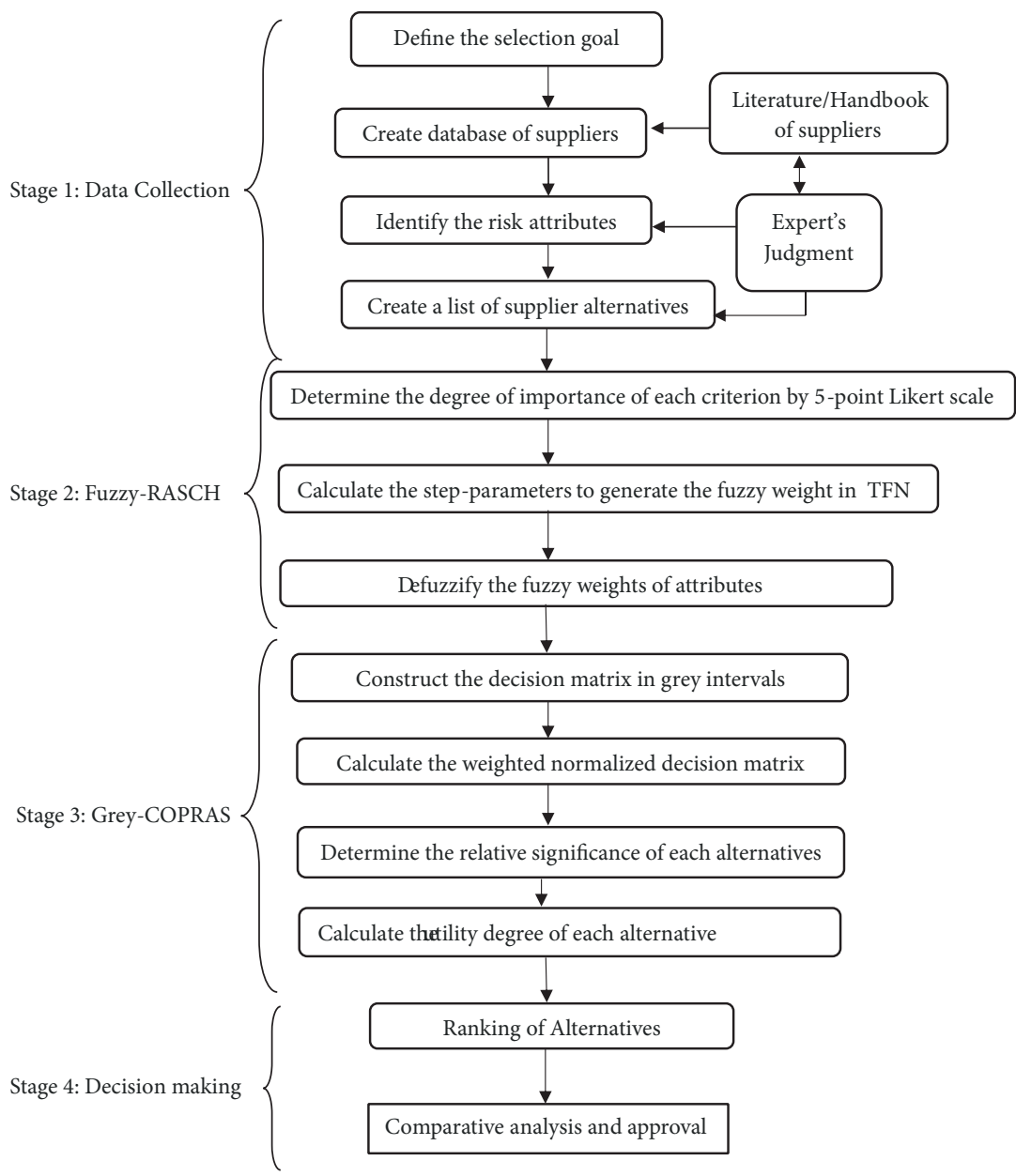

Figure 4. Flowchart of the proposed hybrid fuzzy-Rasch based CORPAS-G model

\subsection{Description of Telecom criteria}

A complete survey is led through the circulation of a complete questionnaire to the managers and the related authorities in the company. After defining all selection criteria and alternative suppliers, the paired judgements

in the questionnaire is made by TFNs to tackle the uncertain linguistic assessment of the data.

- First of all, a team of six expert decision-makers from various domains related to this research is formed, consisting of Telecom Engineer (Expert 1), Marketing Manager (Supply chain) (Expert 2), risk analyst (logistics and HR) (Expert 3), Lawyer (Cybercrime) (Expert 4), Environmental Expert (Expert 5) and an Academic researcher (Expert 6), having top publications related to this field; to works together in defining the criteria, supplier alternative and resultant output. Demographic information is provided in Table 1. 
- In this stage, decision makers define the supplier alternatives from data bank collected from various sources and determines the risk criteria is for the alternatives based on optimal performance ensuring the prerequisite of supply chain and satisfaction of the customers.

Table 1. Demographic characteristics of the expert decision makers

\begin{tabular}{|c|l|l|l|l|l|l|}
\hline $\begin{array}{c}\text { Decision } \\
\text { makers } \\
\text { (Experts) }\end{array}$ & Gender & Age & $\begin{array}{c}\text { Education } \\
\text { background }\end{array}$ & $\begin{array}{c}\text { Service } \\
\text { tenure }\end{array}$ & $\begin{array}{c}\text { Occupational } \\
\text { background }\end{array}$ & Job title \\
\hline $\mathrm{DM}_{1}$ & Male & 45 & Bachelor & $>18$ & Governmental & Senior Telecom Engineer \\
\hline $\mathrm{DM}_{2}$ & Male & 51 & Master & $>23$ & Industrial & Marketing Manager \\
\hline $\mathrm{DM}_{3}$ & Male & 43 & Master & $>17$ & Industrial & Risk analyst \\
\hline $\mathrm{DM}_{4}$ & Female & 37 & Master & $>12$ & Industrial & Legal advisor \\
\hline $\mathrm{DM}_{5}$ & Female & 38 & Master & $>10$ & Governmental & Technical Assistant \\
\hline $\mathrm{DM}_{6}$ & Male & 47 & Doctoral & $>21$ & Academic & Research Associate \\
\hline
\end{tabular}

One of the prime issues in this context is the systematic comparative evaluation of the various supplier alternatives of telecom sector. Especially to cope with environment of cutthroat competition, effective decision- making is a necessity and multi criteria decisionmaking (MCDM) is one such approach, which can evaluates the various dimensions of the telecom service sector supply chain. Few recent works has been done so far in telecommunication sector (Pramod, Banwet 2010; Pramod et al. 2016; Ogundile 2013; Tan et al. 2016; India Risk Survey 2014, 2015, 2016; Badri Ahmadi et al. 2016). Ten potential risk attributes are brought forth through a literature survey by decision experts on supplier selection, namely, Business Espionage $\left(C_{1}\right)$, Workplace health hazards $\left(C_{2}\right)$, Environmental sustainability risk $\left(\mathrm{C}_{3}\right)$, Natural \& Man-made Catastrophe $\left(\mathrm{C}_{4}\right)$, Strikes, Closures \& Unrest (Labour issues) $\left(\mathrm{C}_{5}\right)$, Intellectual property theft $\left(\mathrm{C}_{6}\right)$, Information \& Cyber insecurity risk $\left(\mathrm{C}_{7}\right)$, Terrorism \& Insurgency $\left(\mathrm{C}_{8}\right)$, Logistics problem $\left(\mathrm{C}_{9}\right)$ and Corporate frauds $\left(\mathrm{C}_{10}\right)$. The details given in Table 2 .

Table 2. Identified risk factors in telecom supply chain

\begin{tabular}{|c|l|l|}
\hline No. & \multicolumn{1}{|c|}{ Risk factors } & \multicolumn{1}{|c|}{ References } \\
\hline 1 & Business Espionage $\left(C_{1}\right)$ & $\begin{array}{l}\text { India risk survey 2014, 2015, 2016; } \\
\text { Ogundile 2013 }\end{array}$ \\
\hline 2 & Workplace health hazards $\left(C_{2}\right)$ & $\begin{array}{l}\text { Badri Ahmadi et al. 2016; Viswanadham, } \\
\text { Samvedi 2013 }\end{array}$ \\
\hline 3 & $\begin{array}{l}\text { Environmental sustainability risk }\left(C_{3}\right) \\
(\text { E-waste, Energy costs, End-of-pipe }(\text { EOP }))\end{array}$ & $\begin{array}{l}\text { Badri Ahmadi } \text { et al. 2016; Liou et al. } \\
2015\end{array}$ \\
\hline 4 & Natural \& man-made catastrophe $\left(C_{4}\right)$ & $\begin{array}{l}\text { India risk survey 2014, 2015, 2016; Paul } \\
2015\end{array}$ \\
\hline 5 & Strikes, closures \& Unrest $($ Labour issues $)\left(C_{5}\right)$ & $\begin{array}{l}\text { Viswanadham, Samvedi 2013; Dong, } \\
\text { Cooper 2016 }\end{array}$ \\
\hline 6 & Intellectual property theft $\left(C_{6}\right)$ & Tan et al. 2016; Dong, Cooper 2016 \\
\hline
\end{tabular}


End of Table 2

\begin{tabular}{|c|l|l|}
\hline No. & \multicolumn{1}{|c|}{ Risk factors } & \multicolumn{1}{|c|}{ References } \\
\hline 7 & Information Leakage \& Cyber insecurity risk $\left(C_{7}\right)$ & $\begin{array}{l}\text { India risk survey 2014, 2015, 2016; } \\
\text { Tan } \text { et al. 2016 }\end{array}$ \\
\hline 8 & Terrorism \& Insurgency $\left(C_{8}\right)$ & $\begin{array}{l}\text { India risk survey 2014, 2015, 2016; } \\
\text { Pramod, Banwet 2010 }\end{array}$ \\
\hline 9 & $\begin{array}{l}\text { Logistics problem }\left(C_{9}\right) \text { (include inaccurate } \\
\text { shipment, product damaged in transit) }\end{array}$ & $\begin{array}{l}\text { Dong, Cooper 2016; Viswanadham, } \\
\text { Samvedi 2013 }\end{array}$ \\
\hline 10 & Corporate frauds $\left(C_{10}\right)$ & Ogundile 2013; Pramod et al. 2016 \\
\hline
\end{tabular}

Optimization directions of the above selected criteria $C_{j}(j=1,2, \ldots, 10)$ are as follows: optimization direction $--C_{1}, C_{2}, \ldots, C_{10}-------\rightarrow$ minimum.

Five suppliers $A_{i}(i=1,2, \ldots, 5)$ are chosen as alternatives for decision-making process. The graphical representation of the above hierarchy shown in Figure 5.

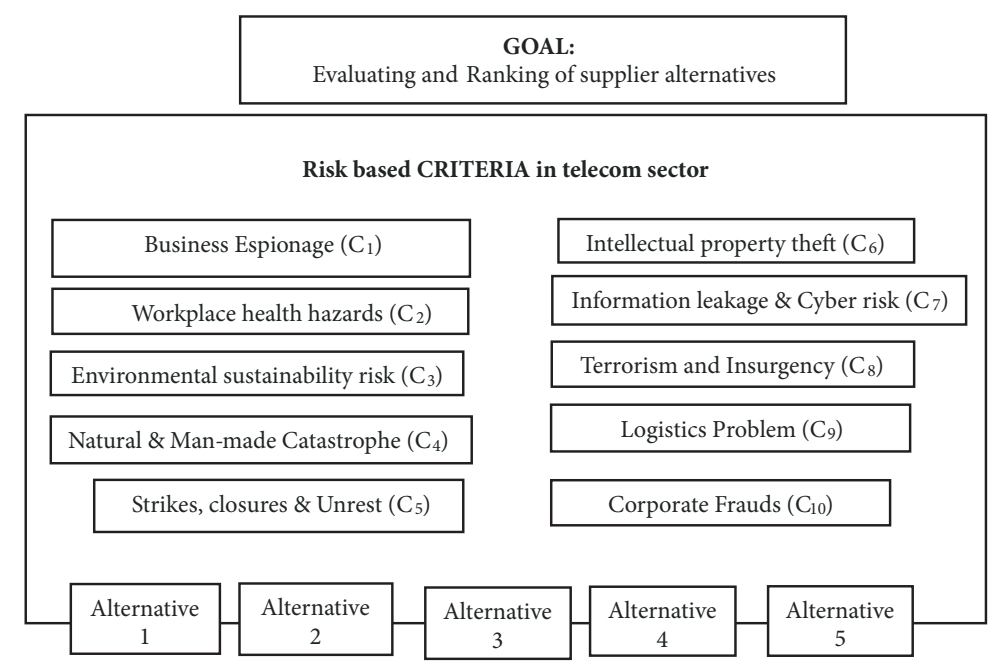

Figure 5. Hierarchical structure for evaluating and ranking the supplier alternatives

\section{Computational steps of the proposed hybrid method}

The aim of the hybrid MCDM model is to quantify ten prominent risk factors $C_{j}(j=1,2$, ..., 10) in Table 2 and rank them as per their criticality to the respective Telecom sector approached by the expert team. The methodology adopted was simple. A risk survey was conducted across various suppliers of Telecom industry in India cutting its territorial boundaries and region, to collect responses from various end professionals.

The study evaluates by initiating six expert decision-makers $D M_{p}(p=1,2, \ldots, 6)$ to specify the degree of importance of ten risk based criteria on a Likert-rating 5 point scale rang- 
ing (from "very low" to "very high") as listed in Table 3. Fuzzy weight of criteria generated by the step parameters $\left(\delta_{i j}\right)$ are defined with Rasch scale model (RSM). Based on Step 3 of method, the study finds that $\tilde{W}_{i j}=\left(\delta_{i j}^{L}, \delta_{i j}^{M}, \delta_{i j}^{U}\right)$ to define Triangular fuzzy numbers (TFN) of the linguistic variables. Table 4 lists the linguistic variables from "very low" to "very high" for TFN obtained from the six experts $D M_{p}(p=1,2, \ldots, 6)$.

The study used arithmetic average method detailed in Eq. (3) of step 4 in the proposed methodology to integrate the fuzzy weight of each expert, and list them in the second column of Table 5. To place all the triangular fuzzy numbers of criteria in positive quadrant, add maximum value (here 8 ) in third column of Table 5 , to nullify the lowermost negative TFN $(-7.467,-4.217,2.633)$ of risk criteria $\left(C_{9}\right)$, as per decision makers suggestions. The model uses Eqs. (4)-(5) of step 5 (Phase II) from above model to transform TFN to crisp numbers and to standardise the weight of risk based attributes respectively. Details shown in fourth and fifth column of Table 5.

The highest risk attribute ranked as number one and lowest risk ranked as number ten. The contribution of each risk factor is highlighted in Figure 6.

Table 3. Degree of importance of weights assigned by six experts to the 10 criteria

\begin{tabular}{|c|c|c|c|c|c|c|}
\hline Criteria & $\begin{array}{c}\text { Expert } \\
\mathrm{DM}_{1}\end{array}$ & $\begin{array}{c}\text { Expert } \\
\mathrm{DM}_{2}\end{array}$ & $\begin{array}{c}\text { Expert } \\
\mathrm{DM}_{3}\end{array}$ & $\begin{array}{c}\text { Expert } \\
\mathrm{DM}_{4}\end{array}$ & $\begin{array}{c}\text { Expert } \\
\mathrm{DM}_{5}\end{array}$ & $\begin{array}{c}\text { Expert } \\
\mathrm{DM}_{6}\end{array}$ \\
\hline$C_{1}$ & 4 & 4 & 5 & 4 & 5 & 4 \\
\hline$C_{2}$ & 4 & 5 & 5 & 5 & 5 & 4 \\
\hline$C_{3}$ & 4 & 3 & 3 & 3 & 3 & 3 \\
\hline$C_{4}$ & 5 & 4 & 3 & 4 & 3 & 4 \\
\hline$C_{5}$ & 4 & 3 & 4 & 4 & 4 & 5 \\
\hline$C_{6}$ & 3 & 2 & 3 & 4 & 5 & 4 \\
\hline$C_{7}$ & 5 & 5 & 5 & 5 & 3 & 4 \\
\hline$C_{8}$ & 4 & 2 & 3 & 2 & 3 & 3 \\
\hline$C_{9}$ & 2 & 2 & 3 & 2 & 3 & 3 \\
\hline$C_{10}$ & 5 & 5 & 3 & 4 & 4 & 3 \\
\hline
\end{tabular}

Table 4. The Linguistic variables of the TFN $\tilde{W}_{i j}=\left(\delta_{i j}^{L}, \delta_{i j}^{M}, \delta_{i j}^{U}\right)$

\begin{tabular}{|c|c|c|c|c|c|}
\hline \multirow[b]{2}{*}{ Experts } & \multicolumn{5}{|c|}{ Five- point step length Likert Scale } \\
\hline & $\begin{array}{c}\text { Very low } \\
1\end{array}$ & $\begin{array}{l}\text { Medium Low } \\
2\end{array}$ & $\begin{array}{l}\text { Medium } \\
3\end{array}$ & $\begin{array}{c}\text { Medium High } \\
4\end{array}$ & $\begin{array}{l}\text { Very High } \\
5\end{array}$ \\
\hline $\mathrm{DM}_{1}$ & - & $(-7,-7,1)$ & $(-7,-1.8,3)$ & $(-4.2,0.7,9)$ & $(-1.5,9,9)$ \\
\hline $\mathrm{DM}_{2}$ & $(-8.3,-8.3,0.5)$ & $(-8.3,-2.1,2.2)$ & $(-4.2,0,4.2)$ & $(-2.1,2,8)$ & $(-0.4,8,8)$ \\
\hline $\mathrm{DM}_{3}$ & - & $(-8.6,-8.6,1)$ & $(-8.6,-1.3,4.1)$ & $(-3.4,1.7,7.4)$ & $(-1,7.4,7.4)$ \\
\hline $\mathrm{DM}_{4}$ & $(-7.3,-7.3,1)$ & $(-7.3,-1.5,2)$ & $(-3.8,-0.1,3.8)$ & $(-2.5,1.3,7.8)$ & $(-1,7.8,7.8)$ \\
\hline $\mathrm{DM}_{5}$ & - & - & $(-5.8,-5.8,2.7)$ & $(-5.8,0,5.8)$ & $(-2.7,5.8,5.8)$ \\
\hline $\mathrm{DM}_{6}$ & - & $(-7.8,-7.8,1)$ & $(-7.8,-1.4,3.8)$ & $(-3.8,1.2,7.5)$ & $(-1,7.5,7.5)$ \\
\hline
\end{tabular}


Applying COPRAS-G approach for alternative ranking, the initial decision support matrix for each expert are first expressed in linguistic terms (defined in Table 6), and shown in Table 7. Table 8 shows the average grey decision-making matrix aggregated using Eqs. (7)-(9) of Step 7 of proposed method.

Table 5. The average fuzzy and defuzzification weights of 10 criteria

\begin{tabular}{|c|c|c|c|c|}
\hline $\begin{array}{c}\text { Criteria } \\
C_{j} \\
(1 \leq j \leq 10)\end{array}$ & $\begin{array}{c}\text { Average weights } \\
\text { in TFNs } \\
\bar{W}_{j}\end{array}$ & $\begin{array}{c}\bar{W}_{j} \\
+ \\
T F N(8,8,8)\end{array}$ & $\begin{array}{c}\text { Defuzzified } \\
\text { weights } \\
B N P_{k}\end{array}$ & $\begin{array}{c}\text { Standardized } \\
\text { weights } \\
W_{k}=S B N P_{k}\end{array}$ \\
\hline$C_{1}$ & $(-2.717,3.067,7.583)$ & $(5.283,11.067,15.583)$ & 10.644 & 0.1394 \\
\hline$C_{2}$ & $(-2.183,5.150,7.583)$ & $(5.817,13.150,15.583)$ & 6.628 & 0.0868 \\
\hline$C_{3}$ & $(-5,733,-0.450,4.600)$ & $(2.267,7.550,12.600)$ & 3.950 & 0.0517 \\
\hline$C_{4}$ & $(-4.050,1.067,6.517)$ & $(3.950,9.067,14.517)$ & 9.178 & 0.1202 \\
\hline$C_{5}$ & $(3.517,3.200,7.583)$ & $(4.483,11.200,15.583)$ & 5.944 & 0.0778 \\
\hline$C_{6}$ & $(-5.483,0.517,5.067)$ & $(2.517,8.517,13.067)$ & 8.033 & 0.1052 \\
\hline$C_{7}$ & $(-2.250,4.600,7.067)$ & $(5.750,12.600,15.067)$ & 11.139 & 0.1458 \\
\hline$C_{8}$ & $(-7.000,-1.900,3.967)$ & $(1.000,6.100,11.967)$ & 6.356 & 0.0832 \\
\hline$C_{9}$ & $(-7.467,-4.217,2.633)$ & $(0.533,3.783,10.633)$ & 4.983 & 0.0652 \\
\hline$C_{10}$ & $(-4.433,2.600,6.417)$ & $(3.567,10.600,14.417)$ & 9.528 & 0.1247 \\
\hline
\end{tabular}

Comparision of risk criteria weights in defuzzified form

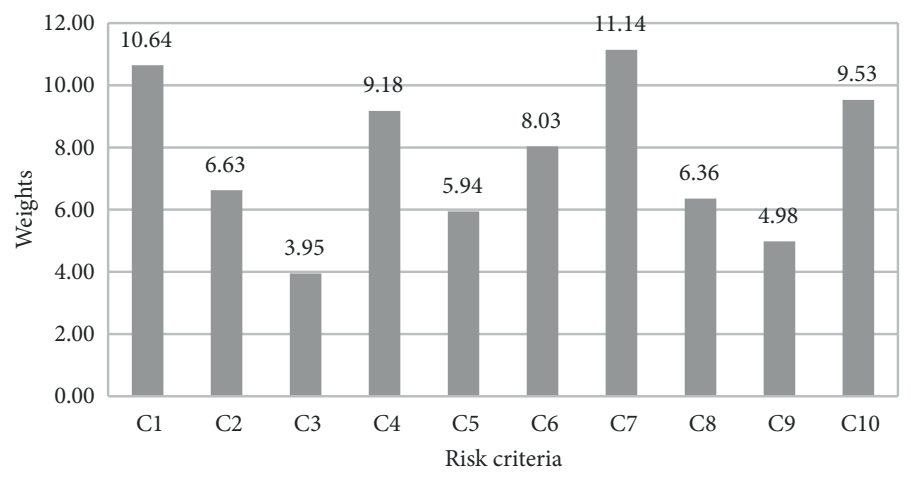

Figure 6. Ranking of ten risk criteria in Telecom sector

Table 6. Linguistic variables and grey numbers for evaluating the alternatives

\begin{tabular}{|l|c|}
\hline \multicolumn{1}{|c|}{ Scale } & Grey numbers \\
\hline Very Poor (VP) & {$[0,1]$} \\
\hline Poor (P) & {$[1,3]$} \\
\hline Medium Poor (MP) & {$[3,4]$} \\
\hline Fair (F) & {$[4,5]$} \\
\hline Medium Good (MG) & {$[5,6]$} \\
\hline Good (G) & {$[6,9]$} \\
\hline Very Good (VG) & {$[9,10]$} \\
\hline
\end{tabular}


Table 7. Attribute rating values for supplier alternatives considering different experts decision

\begin{tabular}{|c|c|c|c|c|c|c|c|c|c|c|c|}
\hline Experts & Alternative & $C_{1}$ & $C_{2}$ & $C_{3}$ & $C_{4}$ & $C 5$ & $C_{6}$ & $C_{7}$ & $C_{8}$ & $C_{9}$ & $C_{10}$ \\
\hline \multirow{5}{*}{$\mathrm{DM}_{1}$} & $A_{1}$ & G & $\mathrm{F}$ & VP & MP & G & VP & $\mathrm{F}$ & G & VP & MP \\
\hline & $A_{2}$ & MG & MG & MG & MG & $\mathrm{F}$ & G & $\mathrm{P}$ & $\mathrm{F}$ & G & VG \\
\hline & $A_{3}$ & G & G & VP & VG & VG & MP & G & VP & $\mathrm{F}$ & $\mathrm{F}$ \\
\hline & $A_{4}$ & $\mathrm{P}$ & MP & VG & MG & G & G & VG & $\mathrm{F}$ & VG & VP \\
\hline & $A_{5}$ & MG & VG & G & VG & $\mathrm{F}$ & $\mathrm{F}$ & MG & VG & G & G \\
\hline \multirow{5}{*}{$\mathrm{DM}_{2}$} & $A_{1}$ & MG & G & MG & MP & G & VP & G & G & $\mathrm{P}$ & G \\
\hline & $A_{2}$ & G & G & G & G & $\mathrm{F}$ & G & MP & $\mathrm{F}$ & VG & VG \\
\hline & $A_{3}$ & MG & VG & $\mathrm{F}$ & G & $\mathrm{F}$ & $\mathrm{P}$ & G & VP & VG & $\mathrm{F}$ \\
\hline & $A_{4}$ & $\mathrm{~F}$ & $\mathrm{MP}$ & VG & MP & VG & $\mathrm{F}$ & $\mathrm{MP}$ & $\mathrm{F}$ & VG & $\mathrm{P}$ \\
\hline & $A_{5}$ & MG & $\mathrm{VG}$ & $\mathrm{F}$ & G & $\mathrm{F}$ & G & MG & $\mathrm{VP}$ & $\mathrm{MG}$ & MG \\
\hline \multirow{5}{*}{$\mathrm{DM}_{3}$} & $A_{1}$ & G & G & $\mathrm{VP}$ & $\mathrm{P}$ & MG & VP & $\mathrm{P}$ & G & $\mathrm{F}$ & $\mathrm{P}$ \\
\hline & $A_{2}$ & $\mathrm{~F}$ & G & G & G & $\mathrm{F}$ & G & MP & G & MG & G \\
\hline & $A_{3}$ & $\mathrm{~F}$ & $\mathrm{VG}$ & $\mathrm{VP}$ & $\mathrm{F}$ & G & G & G & MP & $\mathrm{VP}$ & $\mathrm{G}$ \\
\hline & $A_{4}$ & VG & $\mathrm{MP}$ & G & VG & G & MG & $\mathrm{P}$ & $\mathrm{F}$ & MG & $\mathrm{VP}$ \\
\hline & $A_{5}$ & $\mathrm{~F}$ & VG & $\mathrm{F}$ & G & $\mathrm{G}$ & G & G & $\mathrm{F}$ & G & $\mathrm{G}$ \\
\hline \multirow{5}{*}{$\mathrm{DM}_{4}$} & $A_{1}$ & G & G & G & VG & G & VP & MP & G & $\mathrm{VP}$ & $\mathrm{F}$ \\
\hline & $A_{2}$ & MG & G & G & $\mathrm{F}$ & $\mathrm{F}$ & G & $\mathrm{MP}$ & $\mathrm{F}$ & $\mathrm{F}$ & VG \\
\hline & $A_{3}$ & $\mathrm{~F}$ & $\mathrm{VG}$ & $\mathrm{F}$ & G & $\mathrm{F}$ & $\mathrm{MP}$ & G & VG & $\mathrm{G}$ & $\mathrm{P}$ \\
\hline & $A_{4}$ & $\mathrm{MG}$ & $\mathrm{G}$ & $\mathrm{F}$ & G & $\mathrm{F}$ & $\mathrm{VG}$ & MP & $\mathrm{VP}$ & MG & $\mathrm{P}$ \\
\hline & $A_{5}$ & $\mathrm{G}$ & MG & $\mathrm{F}$ & VG & $\mathrm{VG}$ & $\mathrm{P}$ & $\mathrm{P}$ & $\mathrm{P}$ & $\mathrm{F}$ & $\mathrm{G}$ \\
\hline \multirow{5}{*}{$\mathrm{DM}_{5}$} & $A_{1}$ & G & VG & $\mathrm{VP}$ & G & $\mathrm{F}$ & $\mathrm{VP}$ & $\mathrm{G}$ & MP & $\mathrm{VG}$ & $\mathrm{F}$ \\
\hline & $A_{2}$ & $\mathrm{~F}$ & $\mathrm{G}$ & $\mathrm{G}$ & $\mathrm{F}$ & $\mathrm{F}$ & G & MP & $\mathrm{MP}$ & $\mathrm{VG}$ & $\mathrm{G}$ \\
\hline & $A_{3}$ & MP & VG & $\mathrm{F}$ & $\mathrm{P}$ & G & G & $\mathrm{G}$ & $\mathrm{VP}$ & G & $\mathrm{VP}$ \\
\hline & $A_{4}$ & $\mathrm{G}$ & $\mathrm{VG}$ & $\mathrm{VG}$ & $\mathrm{MP}$ & G & MG & MP & VG & $\mathrm{F}$ & $\mathrm{P}$ \\
\hline & $A_{5}$ & MG & MG & G & MG & $\mathrm{F}$ & $\mathrm{F}$ & $\mathrm{MP}$ & VG & G & $\mathrm{P}$ \\
\hline \multirow{5}{*}{$\mathrm{DM}_{6}$} & $A_{1}$ & MG & MG & G & G & $\mathrm{F}$ & $\mathrm{P}$ & $\mathrm{F}$ & $\mathrm{F}$ & VG & $\mathrm{F}$ \\
\hline & $A_{2}$ & G & $\mathrm{F}$ & G & $\mathrm{F}$ & $\mathrm{F}$ & G & $\mathrm{MP}$ & G & $\mathrm{VG}$ & VG \\
\hline & $A_{3}$ & $\mathrm{~F}$ & G & $\mathrm{F}$ & PP & G & G & G & $\mathrm{F}$ & $\mathrm{F}$ & $\mathrm{P}$ \\
\hline & $A_{4}$ & MG & G & VP & MG & G & G & $\mathrm{F}$ & $\mathrm{F}$ & $\mathrm{F}$ & VP \\
\hline & $A_{5}$ & $\mathrm{MG}$ & MG & $\mathrm{F}$ & $\mathrm{G}$ & $\mathrm{F}$ & $\mathrm{F}$ & $\mathrm{F}$ & $\mathrm{VG}$ & MG & $\mathrm{VP}$ \\
\hline
\end{tabular}


Table 8. Average grey decision making matrix

\begin{tabular}{|c|c|c|c|c|c|c|c|c|c|c|}
\hline & \multicolumn{10}{|c|}{ Criteria } \\
\hline \multirow{2}{*}{ Alternatives } & $\begin{array}{c}C_{1} \\
\mathrm{~min}\end{array}$ & $\begin{array}{c}C_{2} \\
\mathrm{~min}\end{array}$ & $\begin{array}{c}C_{3} \\
\mathrm{~min}\end{array}$ & $\begin{array}{c}C_{4} \\
\mathrm{~min}\end{array}$ & $\begin{array}{c}C_{5} \\
\mathrm{~min}\end{array}$ & $\begin{array}{c}C_{6} \\
\mathrm{~min}\end{array}$ & $\begin{array}{c}C_{7} \\
\mathrm{~min}\end{array}$ & $\begin{array}{c}C_{8} \\
\mathrm{~min}\end{array}$ & $\begin{array}{c}C_{9} \\
\mathrm{~min}\end{array}$ & $\begin{array}{c}C_{10} \\
\mathrm{~min}\end{array}$ \\
\hline \multirow{2}{*}{$A_{1}$} & {$[5.67$,} & {$[6.00$,} & {$[2.83$,} & {$[4.67$,} & {$[5.33$,} & {$[0.17$,} & {$[4.00$,} & {$[5.17$,} & {$[3.83$,} & {$[4.00$,} \\
& $8.00]$ & $8.00]$ & $4.50]$ & $6.50]$ & $7.33]$ & $1.33]$ & $5.83]$ & $7.50]$ & $5.00]$ & $5.50]$ \\
\hline \multirow{2}{*}{$A_{2}$} & {$[5.00$,} & {$[5.17$,} & {$[5.83$,} & {$[4.83$,} & {$[4.00$,} & {$[6.00$,} & {$[2.67$,} & {$[4.50$,} & {$[7.00$,} & {$[8.00$,} \\
& $6.67]$ & $7.17]$ & $8.50]$ & $6.50]$ & $5.00]$ & $9.00]$ & $3.83]$ & $6.17]$ & $8.33]$ & $9.67]$ \\
\hline \multirow{2}{*}{$A_{3}$} & {$[4.33$,} & {$[7.50$,} & {$[2.67$,} & {$[4.50$,} & {$[5.67$,} & {$[3.83$,} & {$[6.00$,} & {$[2.67$,} & {$[4.83$,} & {$[2.67$,} \\
& $5.67]$ & $9.50]$ & $3.67]$ & $6.50]$ & $7.33]$ & $6.17]$ & $9.00]$ & $3.67]$ & $6.50]$ & $4.33]$ \\
\hline \multirow{2}{*}{$A_{4}$} & {$[5.17$,} & {$[5.33$,} & {$[6.17$,} & {$[5.17$,} & {$[6.17$,} & {$[5.83$,} & {$[3.83$,} & {$[4.17$,} & {$[6.17$,} & {$[0.50$,} \\
& $7.00]$ & $7.00]$ & $7.50]$ & $6.50]$ & $8.50]$ & $7.50]$ & $5.00]$ & $5.17]$ & $7.17]$ & $2.00]$ \\
\hline \multirow{2}{*}{$A_{5}$} & {$[5.00$,} & {$[6.50$,} & {$[4.67$,} & {$[6.83$,} & {$[6.00$,} & {$[4.17$,} & {$[4.00$,} & {$[6.83$,} & {$[5.33$,} & {$[4.00$,} \\
& $6.33]$ & $7.83]$ & $6.33]$ & $8.83]$ & $7.33]$ & $6.00]$ & $5.50]$ & $8.00]$ & $7.33]$ & $6.17]$ \\
\hline
\end{tabular}

Next, following Step 8 of section 2, the normalized decision-making matrix (Table 9), and weighted decision-making matrix (Table 10) are constructed. The relative significance $\left(Q_{i}\right) \forall$ $i=1,2, \ldots, 5$ for each supplier alternative $A_{i}(i=1,2, \ldots, 5)$ are calculated using Eq. (16)-(17) in Step 9, after calculating $\left(P_{i}\right)$ using Eq. $(14),\left(R_{i}\right)$ using Eq. (15). The utility degree $\left(N_{i}\right)$ of each alternative calculated as per Eq. (19) for ranking the alternatives. The overall results of the COPRAS-G method and ranking is summarized in Table 11.

Table 9. Normalized grey decision making matrix

\begin{tabular}{|c|c|c|c|c|c|c|c|c|c|c|}
\hline & $C_{1}$ & $C_{2}$ & $C_{3}$ & $C_{4}$ & $C_{5}$ & $C_{6}$ & $C_{7}$ & $C_{8}$ & $C_{9}$ & $C_{10}$ \\
\hline \multirow{2}{*}{$A_{1}$} & {$[0.1927$,} & {$[0.1714$,} & {$[0.1076$,} & {$[0.1535$,} & {$[0.1701$,} & {$[0.0068$,} & {$[0.1611$,} & {$[0.1920$,} & {$[0.1242$,} & {$[0.1708$,} \\
& $0.2719]$ & $0.2286]$ & $0.1709]$ & $0.2137]$ & $0.2340]$ & $0.0532]$ & $0.2348]$ & $0.2786]$ & $0.1621]$ & $0.2348]$ \\
\hline \multirow{2}{*}{$A_{2}$} & {$[0.1700$,} & {$[0.1477$,} & {$[0.2214$,} & {$[0.1588$,} & {$[0.1277$,} & {$[0.2400$,} & {$[0.1075$,} & {$[0.1671$,} & {$[0.2269$,} & {$[0.3416$,} \\
& $0.2267]$ & $0.2049]$ & $0.3228]$ & $0.2137]$ & $0.1596]$ & $0.3600]$ & $0.1542]$ & $0.2292]$ & $0.2701]$ & $0.4129]$ \\
\hline \multirow{2}{*}{$A_{3}$} & {$[0.1472$,} & {$[0.2143$,} & {$[0.1014$,} & {$[0.1480$,} & {$[0.1810$,} & {$[0.1532$,} & {$[0.2416$,} & {$[0.0992$,} & {$[0.1566$,} & {$[0.1140$,} \\
& $0.1927]$ & $0.2714]$ & $0.1394]$ & $0.2137]$ & $0.2340]$ & $0.2468]$ & $0.3625]$ & $0.1363]$ & $0.2107]$ & $0.1849]$ \\
\hline \multirow{2}{*}{$A_{4}$} & {$[0.1757$,} & {$[0.1523$,} & {$[0.2343$,} & {$[0.1700$,} & {$[0.1969$,} & {$[0.2332$,} & {$[0.1542$,} & {$[0.1549$,} & {$[0.2005$,} & {$[0.0213$,} \\
& $0.2379]$ & $0.2000]$ & $0.2848]$ & $0.2137]$ & $0.2713]$ & $0.3000]$ & $0.2014]$ & $0.1920]$ & $0.2325]$ & $0.0854]$ \\
\hline \multirow{2}{*}{$A_{5}$} & {$[0.1700$,} & {$[0.1857$,} & {$[0.1773$,} & {$[0.2246$,} & {$[0.1915$,} & {$[0.1668$,} & {$[0.1611$,} & {$[0.2537$,} & {$[0.1793$,} & {$[0.1708$,} \\
& $0.2152]$ & $0.2237]$ & $0.2404]$ & $0.2903]$ & $0.2340]$ & $0.2400]$ & $0.2215]$ & $0.2971]$ & $0.2376]$ & $0.2635]$ \\
\hline
\end{tabular}

Table 10. Weighted Normalized grey decision support matrix for the alternatives

\begin{tabular}{|c|c|c|c|c|c|c|c|c|c|c|}
\hline & $C_{1}$ & $C_{2}$ & $C_{3}$ & $C_{4}$ & $C_{5}$ & $C_{6}$ & $C_{7}$ & $C_{8}$ & $C_{9}$ & $C_{10}$ \\
\hline \multirow{2}{*}{$A_{1}$} & {$[0.0269$,} & {$[0.0149$,} & {$[0.0056$,} & {$[0.0185$,} & {$[0.0132$,} & {$[0.0007$,} & {$[0.0235$,} & {$[0.0160$,} & {$[0.0081$,} & {$[0.0213$,} \\
& $0.0379]$ & $0.0198]$ & $0.0088]$ & $0.0257]$ & $0.0182]$ & $0.0056]$ & $0.0342]$ & $0.0232]$ & $0.0106]$ & $0.0293]$ \\
\hline \multirow{2}{*}{$A_{2}$} & {$[0.0237$,} & {$[0.0128$,} & {$[0.0114$,} & {$[0.0191$,} & {$[0.0099$,} & {$[0.0252$,} & {$[0.0157$,} & {$[0.0139$,} & {$[0.0148$,} & {$[0.0426$,} \\
& $0.0316]$ & $0.0178]$ & $0.0167]$ & $0.0257]$ & $0.0124]$ & $0.0379]$ & $0.0225]$ & $0.0191]$ & $0.0176]$ & $0.0515]$ \\
\hline \multirow{2}{*}{$A_{3}$} & {$[0.0205$,} & {$[0.0186$,} & {$[0.0052$,} & {$[0.0178$,} & {$[0.0141$,} & {$[0.0161$,} & {$[0.0352$,} & {$[0.0083$,} & {$[0.0103$,} & {$[0.0142$,} \\
& $0.0269]$ & $0.0236]$ & $0.0072]$ & $0.0257]$ & $0.0182]$ & $0.0260]$ & $0.0528]$ & $0.0113]$ & $0.0137]$ & $0.0231]$ \\
\hline
\end{tabular}


End of Table 10

\begin{tabular}{|c|c|c|c|c|c|c|c|c|c|c|}
\hline & $C_{1}$ & $C_{2}$ & $C_{3}$ & $C_{4}$ & $C_{5}$ & $C_{6}$ & $C_{7}$ & $C_{8}$ & $C_{9}$ & $C_{10}$ \\
\hline \multirow{2}{*}{$A_{4}$} & {$[0.0245$,} & {$[0.0132$,} & {$[0.0121$,} & {$[0.0204$,} & {$[0.0153$,} & {$[0.0245$,} & {$[0.0225$,} & {$[0.0129$,} & {$[0.0130$,} & {$[0.0027$,} \\
& $0.0332]$ & $0.0174]$ & $0.0147]$ & $0.0257]$ & $0.0211]$ & $0.0316]$ & $0.0294]$ & $0.0160]$ & $0.0152]$ & $0.0107]$ \\
\hline \multirow{2}{*}{$A_{5}$} & {$[0.0237$,} & {$[0.0161$,} & {$[0.0092$,} & {$[0.0270$,} & {$[0.0149$,} & {$[0.0175$,} & {$[0.0235$,} & {$[0.0211$,} & {$[0.0117$} & {$[0.0213$,} \\
& $0.0300]$ & $0.0194]$ & $0.0124]$ & $0.0349]$ & $0.0182]$ & $0.0252]$ & $0.0323]$ & $0.0247]$ & $0.0155]$ & $0.0329]$ \\
\hline
\end{tabular}

Table 11. Decision results according to a COPRAS-G method

\begin{tabular}{|c|c|c|c|c|c|}
\hline Alternatives & $\mathrm{P}_{\mathrm{i}}$ & $R_{i}$ & $Q_{i}$ & $\left(N_{i}\right) \%$ & Rank \\
\hline$A_{1}$ & 0 & 0.1809 & 0.2197 & 100 & 1 \\
\hline$A_{2}$ & 0 & 0.2210 & 0.1799 & 82 & 5 \\
\hline$A_{3}$ & 0 & 0.1944 & 0.2046 & 93 & 3 \\
\hline$A_{4}$ & 0 & 0.1880 & 0.2115 & 96 & 2 \\
\hline$A_{5}$ & 0 & 0.2158 & 0.1843 & 84 & 4 \\
\hline
\end{tabular}

\section{Result and discussion}

Using COPRAS-G, an initial assessment of the feasibility of selection of supplier alternatives in telecom sector is conducted. The analysis compared five alternatives based on ten weighted decision attributes calculated by fuzzy-Rasch model. Based on the judgement of six expert decision makers $D M_{p}(p=1,2, \ldots, 6)$, ranking of the priorities of the supplier alternatives is compiled, and as shown in Table 11 , alternative $\left(A_{1}\right)$ with a utility degree $(100 \%)$ is selected as a first choice optimal supplier. Alternative $\left(A_{4}\right)$ with a utility degree $(96 \%)$ and alternative $\left(A_{3}\right)$ with utility degree $(93 \%)$ are selected as second and third supplier alternative respectively. Alternatives $\left(A_{5}\right)$ and $\left(A_{2}\right)$ with utility degree of $79 \%$ and $69 \%$ respectively, are selected as fourth and fifth choice for material supplier.

The results in ranking alternatives in MCDM method is also depended on the relative importance attached to the values of the weight coefficients of the specific criteria. To measure the influence of criteria weight to final ranking of alternatives, we perform a sensitivity analysis on changed weights of criteria. In our paper, 12 different sets $\operatorname{Set} l(l=1,2, \ldots, 12)$ of risk criteria $C_{j}(j=1,2, \ldots, 10)$ weight are taken, mentioning the prioritized ones in bold numbers and detailed in Table 12. The corresponding alternative ranking using COPRAS-G MCDM method for different set of criteria weight shown in Table 13.

The result shows that alternative $\left(A_{1}\right)$ has a maximum priority in almost all the situations and assigning different weights (priorities) to the criteria leads to different rankings. Each criteria weight has influential effect the ranking of alternatives. For example, prioritizing the weights of criteria $C_{2}$ and $C_{7}$ has improve the ranking of $\left(A_{2}\right)$ and $\left(A_{4}\right)$ from 5 th to 3 rd position and 4 th to 1 st position, respectively. Similarly, other changes in criteria weights are shown in Figure 7 with its corresponding effect on ranking of alternatives in Figure 8. 
Table 12. Simulated weights of risk criteria in different sets

\begin{tabular}{|l|c|c|c|c|c|c|c|c|c|c|}
\hline & $C_{1}$ & $C_{2}$ & $C_{3}$ & $C_{4}$ & $C_{5}$ & $C_{6}$ & $C_{7}$ & $C_{8}$ & $C_{9}$ & $C_{10}$ \\
\hline Set 1 & $\mathbf{0 . 1 3 9 4}$ & 0.0868 & 0.0517 & $\mathbf{0 . 1 2 0 2}$ & 0.0778 & 0.1052 & $\mathbf{0 . 1 4 5 8}$ & 0.0832 & 0.0652 & $\mathbf{0 . 1 2 4 7}$ \\
\hline Set 2 & 0.0239 & $\mathbf{0 . 1 4 7 0}$ & $\mathbf{0 . 1 4 5 0}$ & 0.0735 & 0.1212 & 0.0215 & 0.0639 & $\mathbf{0 . 1 3 8 7}$ & 0.1200 & $\mathbf{0 . 1 4 5 3}$ \\
\hline Set 3 & 0.1117 & 0.0061 & $\mathbf{0 . 1 4 4 6}$ & $\mathbf{0 . 1 5 9 0}$ & 0.1156 & $\mathbf{0 . 1 2 9 0}$ & $\mathbf{0 . 1 2 6 5}$ & 0.0668 & 0.1116 & 0.0291 \\
\hline Set 4 & 0.1024 & $\mathbf{0 . 2 1 6 1}$ & 0.0432 & 0.0626 & 0.0345 & 0.0323 & $\mathbf{0 . 2 0 6 3}$ & $\mathbf{0 . 1 3 7 6}$ & $\mathbf{0 . 1 3 0 5}$ & 0.0344 \\
\hline Set 5 & 0.1214 & 0.0658 & $\mathbf{0 . 1 6 5 4}$ & 0.0420 & $\mathbf{0 . 1 5 2 5}$ & 0.0408 & 0.0818 & $\mathbf{0 . 1 3 8 9}$ & $\mathbf{0 . 1 7 3 3}$ & 0.0180 \\
\hline Set 6 & 0.0185 & 0.1132 & 0.0856 & $\mathbf{0 . 1 3 4 9}$ & $\mathbf{0 . 1 2 3 8}$ & $\mathbf{0 . 1 5 6 5}$ & $\mathbf{0 . 1 5 4 3}$ & 0.0579 & 0.1210 & 0.0343 \\
\hline Set 7 & 0.0393 & 0.0515 & $\mathbf{0 . 1 9 0 3}$ & 0.0062 & 0.1052 & 0.0360 & $\mathbf{0 . 2 1 0 1}$ & $\mathbf{0 . 1 5 3 0}$ & $\mathbf{0 . 1 0 7 4}$ & 0.1011 \\
\hline Set 8 & 0.0860 & $\mathbf{0 . 1 2 7 1}$ & 0.0046 & 0.2897 & 0.0492 & 0.0313 & $\mathbf{0 . 1 0 9 7}$ & 0.0583 & $\mathbf{0 . 1 4 4 2}$ & $\mathbf{0 . 1 0 0 0}$ \\
\hline Set 9 & $\mathbf{0 . 1 5 2 4}$ & $\mathbf{0 . 1 4 7 4}$ & 0.0084 & 0.1181 & 0.0431 & 0.0677 & 0.0877 & $\mathbf{0 . 1 5 0 9}$ & 0.0669 & $\mathbf{0 . 1 5 7 4}$ \\
\hline Set 10 & 0.0597 & $\mathbf{0 . 1 3 8 9}$ & $\mathbf{0 . 1 3 2 0}$ & 0.1068 & $\mathbf{0 . 1 3 8 3}$ & 0.1320 & 0.0353 & 0.0254 & $\mathbf{0 . 1 9 7 9}$ & 0.0339 \\
\hline Set 11 & $\mathbf{0 . 1 6 0 1}$ & 0.0935 & 0.0474 & 0.1064 & $\mathbf{0 . 1 1 9 7}$ & 0.0300 & $\mathbf{0 . 1 4 6 4}$ & 0.0562 & 0.0955 & $\mathbf{0 . 1 4 4 8}$ \\
\hline Set 12 & 0.0720 & 0.0798 & 0.0651 & $\mathbf{0 . 1 3 5 9}$ & 0.1118 & $\mathbf{0 . 1 3 7 4}$ & $\mathbf{0 . 1 6 6 0}$ & $\mathbf{0 . 1 7 3 1}$ & 0.0342 & 0.0247 \\
\hline
\end{tabular}

Note: ${ }^{*}$ Values in bold numbers indicates criteria which are prioritized for that particular set.

Table 13. Supplier alternatives ranking for different sets of criteria weight

\begin{tabular}{|c|c|c|c|c|c|c|c|c|c|c|c|c|}
\hline \multirow{2}{*}{ Alternative } & \multicolumn{8}{|c|}{ Ranking of the alternatives by different simulated criteria weight } \\
\cline { 2 - 17 } & Set 1 & Set 2 & Set 3 & Set 4 & Set 5 & Set 6 & Set 7 & Set 8 & Set 9 & Set 10 & Set 11 & Set 12 \\
\hline$A_{1}$ & 1 & 2 & 1 & 2 & 2 & 1 & 1 & 2 & 3 & 1 & 2 & 1 \\
\hline$A_{2}$ & 5 & 5 & 5 & 3 & 3 & 4 & 5 & 4 & 5 & 3 & 5 & 3 \\
\hline$A_{3}$ & 3 & 1 & 2 & 4 & 1 & 2 & 2 & 3 & 2 & 2 & 3 & 2 \\
\hline$A_{4}$ & 2 & 3 & 4 & 1 & 4 & 3 & 3 & 1 & 1 & 5 & 1 & 4 \\
\hline$A_{5}$ & 4 & 4 & 3 & 5 & 5 & 5 & 4 & 5 & 4 & 4 & 4 & 5 \\
\hline
\end{tabular}

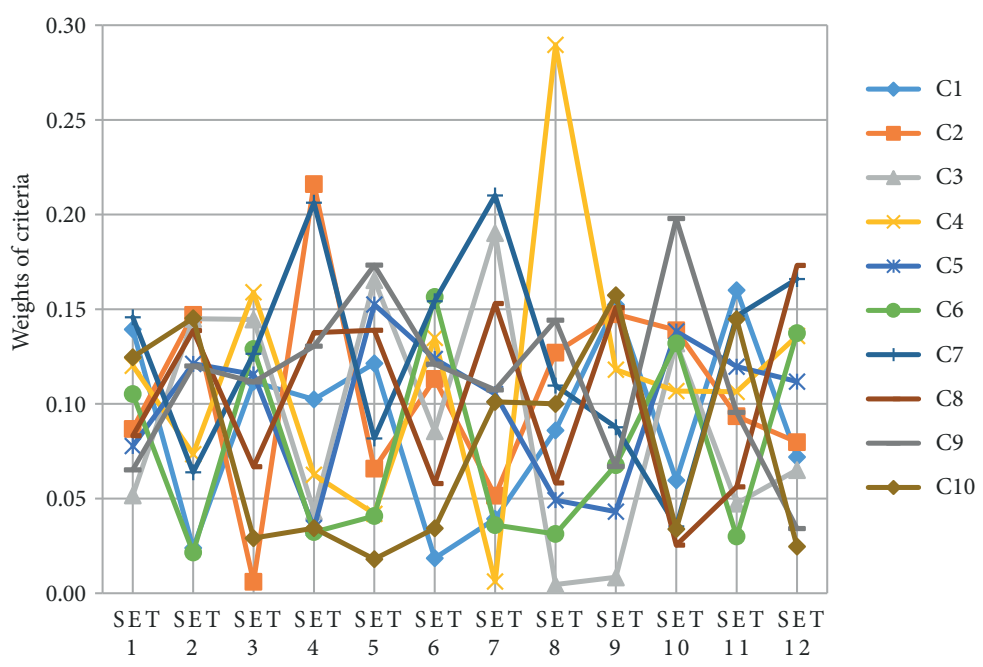

Figure 7. Ten sets of the criteria weights for sensitivity analysis 


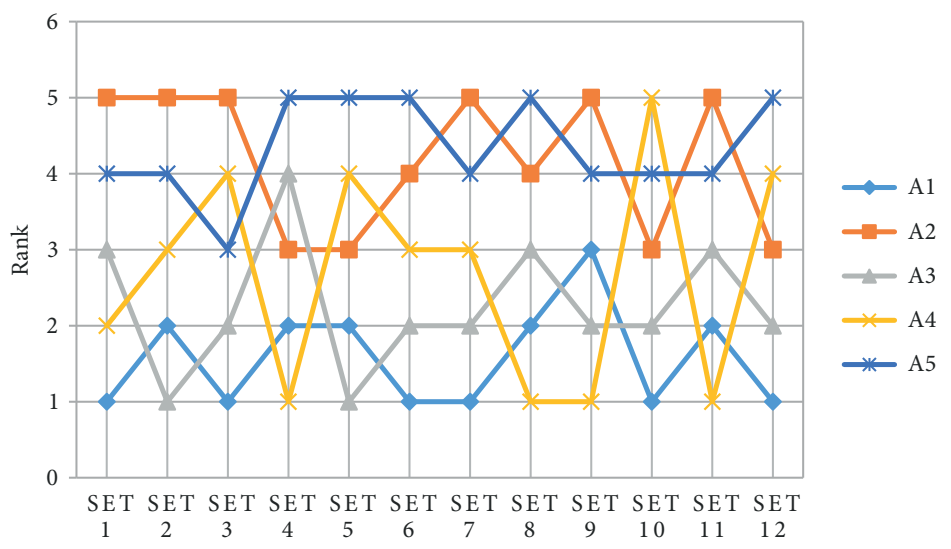

Figure 8. Sensitivity analysis of five sets of alternatives

From the above, it is conform that the supplier alternative $A_{i}(i=1,2, \ldots, 5)$ are dependent and sensitive to these risk preference of criteria weights thus showing stability in the ranking method.

To assess the consistency and reliability between different ranking patterns obtained by different MCDM methods, a comparative sensitivity analysis is also performed based on Keshavarz Ghorabaee et al. (2016b), for the given set of alternatives. In this paper, five supplier alternatives $A_{i}(i=1,2, \ldots, 5)$ are assessed under twelve different sets of simulated risk based criteria weights (Table 12), for which we selected existing MCDM methods in grey domain viz. TOPSIS-G (Oztaysi 2014), ARAS-G (Turskis, Zavadskas 2010), VIKOR-G (Chatterjee, P., Chatterjee, R. 2012). Data from Table 8 is selected to rank the alternative suppliers using COPRAS-G and above selected MCDM. The detailed result is shown in Table 14.

Table 14. The ranking results with different methods in different sets

\begin{tabular}{|c|c|c|c|c|c|}
\hline \multirow{3}{*}{ Set No. } & \multirow{2}{*}{ Supplier Alternatives } & \multicolumn{4}{|c|}{ MCDM methods } \\
\cline { 3 - 6 } & & COPRAS-G & TOPSIS-G & ARAS-G & VIKOR-G \\
\hline \multirow{4}{*}{1} & $A_{1}$ & 1 & 2 & 2 & 1 \\
\cline { 2 - 6 } & $A_{2}$ & 5 & 3 & 4 & 3 \\
\cline { 2 - 6 } & $A_{3}$ & 3 & 4 & 3 & 2 \\
\cline { 2 - 6 } & $A_{4}$ & 2 & 1 & 1 & 4 \\
\hline \multirow{3}{*}{2} & $A_{5}$ & 4 & 5 & 5 & 5 \\
\cline { 2 - 6 } & $A_{1}$ & 2 & 3 & 1 & 2 \\
\cline { 2 - 6 } & $A_{2}$ & 5 & 4 & 3 & 3 \\
\cline { 2 - 6 } & $A_{3}$ & 3 & 1 & 2 & 4 \\
\hline
\end{tabular}


Continue of Table 14

\begin{tabular}{|c|c|c|c|c|c|}
\hline \multirow{2}{*}{ Set No. } & \multirow{2}{*}{ Supplier Alternatives } & \multicolumn{4}{|c|}{ MCDM methods } \\
\hline & & COPRAS-G & TOPSIS-G & ARAS-G & VIKOR-G \\
\hline \multirow{5}{*}{3} & $A_{1}$ & 1 & 1 & 1 & 2 \\
\hline & $A_{2}$ & 5 & 3 & 3 & 5 \\
\hline & $A_{3}$ & 2 & 2 & 4 & 3 \\
\hline & $A_{4}$ & 4 & 4 & 2 & 1 \\
\hline & $A_{5}$ & 3 & 5 & 5 & 4 \\
\hline \multirow{5}{*}{4} & $A_{1}$ & 2 & 3 & 2 & 1 \\
\hline & $A_{2}$ & 3 & 1 & 4 & 5 \\
\hline & $A_{3}$ & 4 & 4 & 3 & 4 \\
\hline & $A_{4}$ & 1 & 2 & 1 & 3 \\
\hline & $A_{5}$ & 5 & 5 & 5 & 2 \\
\hline \multirow{5}{*}{5} & $A_{1}$ & 2 & 2 & 1 & 1 \\
\hline & $A_{2}$ & 3 & 3 & 4 & 5 \\
\hline & $A_{3}$ & 1 & 1 & 2 & 2 \\
\hline & $A_{4}$ & 4 & 4 & 3 & 4 \\
\hline & $A_{5}$ & 5 & 5 & 5 & 3 \\
\hline \multirow{5}{*}{6} & $A_{1}$ & 1 & 1 & 1 & 3 \\
\hline & $A_{2}$ & 4 & 2 & 5 & 1 \\
\hline & $A_{3}$ & 2 & 3 & 3 & 4 \\
\hline & $A_{4}$ & 3 & 4 & 2 & 2 \\
\hline & $A_{5}$ & 5 & 5 & 4 & 5 \\
\hline \multirow{5}{*}{7} & $A_{1}$ & 1 & 2 & 1 & 2 \\
\hline & $A_{2}$ & 5 & 3 & 4 & 5 \\
\hline & $A_{3}$ & 2 & 1 & 2 & 4 \\
\hline & $A_{4}$ & 3 & 4 & 3 & 1 \\
\hline & $A_{5}$ & 4 & 5 & 5 & 3 \\
\hline \multirow{5}{*}{8} & $A_{1}$ & 2 & 1 & 1 & 4 \\
\hline & $A_{2}$ & 4 & 3 & 4 & 2 \\
\hline & $A_{3}$ & 3 & 4 & 3 & 1 \\
\hline & $A_{4}$ & 1 & 2 & 2 & 3 \\
\hline & $A_{5}$ & 5 & 5 & 5 & 5 \\
\hline \multirow{5}{*}{9} & $A_{1}$ & 3 & 4 & 2 & 2 \\
\hline & $A_{2}$ & 5 & 3 & 3 & 4 \\
\hline & $A_{3}$ & 2 & 2 & 4 & 3 \\
\hline & $A_{4}$ & 1 & 1 & 1 & 1 \\
\hline & $A_{5}$ & 4 & 5 & 5 & 5 \\
\hline
\end{tabular}


End of Table 14

\begin{tabular}{|c|c|c|c|c|c|}
\hline \multirow{3}{*}{ Set No. } & \multirow{2}{*}{ Supplier Alternatives } & \multicolumn{4}{|c|}{ MCDM methods } \\
\cline { 2 - 6 } & & COPRAS-G & TOPSIS-G & ARAS-G & VIKOR-G \\
\hline \multirow{4}{*}{10} & $A_{1}$ & 1 & 1 & 1 & 2 \\
\cline { 2 - 6 } & $A_{2}$ & 3 & 3 & 3 & 4 \\
\cline { 2 - 6 } & $A_{3}$ & 2 & 2 & 2 & 3 \\
\cline { 2 - 6 } & $A_{4}$ & 5 & 4 & 4 & 1 \\
\hline \multirow{4}{*}{11} & $A_{5}$ & 4 & 5 & 5 & 5 \\
\cline { 2 - 6 } & $A_{1}$ & 2 & 4 & 2 & 4 \\
\cline { 2 - 6 } & $A_{2}$ & 5 & 2 & 3 & 3 \\
\cline { 2 - 6 } & $A_{3}$ & 3 & 3 & 1 & 2 \\
\hline \multirow{4}{*}{12} & $A_{4}$ & 4 & 5 & 5 & 5 \\
\cline { 2 - 6 } & $A_{5}$ & 1 & 1 & 1 & 3 \\
\cline { 2 - 6 } & $A_{1}$ & 3 & 2 & 3 & 2 \\
\cline { 2 - 6 } & $A_{2}$ & 2 & 3 & 4 & 4 \\
\cline { 2 - 6 } & $A_{3}$ & 4 & 4 & 5 & \\
\hline
\end{tabular}

To compare the ranking results obtained from the different methods, the Spearman's rank correlation coefficient $\left(r_{s}\right)$ is applied on them, the interpretation of which is given in Table 15. Table 16 shows correlation coefficient value between the ranking results of COPRAS-G and selected MCDM methods for 12 different set of criteria weights.

Table 15. Interpretation of the correlation coefficient values $\left(r_{s}\right)$

\begin{tabular}{|c|c|}
\hline Range & Relationship \\
\hline$r_{s} \geq 0.8$ & Very strong \\
\hline $0.6 \leq r_{s} \leq 0.8$ & Strong \\
\hline $0.4 \leq r_{s} \leq 0.6$ & Moderate \\
\hline $0.2 \leq r_{s} \leq 0.4$ & Weak \\
\hline$r_{s} \leq 0.2$ & Very Weak \\
\hline
\end{tabular}

Table 16. Correlation coefficients between the ranking results of COPRAS-G and the other methods

\begin{tabular}{|l|c|c|c|c|c|c|c|c|c|c|c|c|}
\hline \multirow{3}{*}{ Method } & \multicolumn{10}{|c|}{$r_{s}$} \\
\cline { 2 - 16 } & Set 1 & Set 2 & Set 3 & Set 4 & Set 5 & Set 6 & Set 7 & Set 8 & Set 9 & Set 10 & Set 11 & Set 12 \\
\hline TOPSIS-G & 0.933 & 0.933 & 0.933 & 0.933 & 0.95 & 1 & 0.95 & 0.933 & 0.967 & 0.950 & 0.983 & 0.883 \\
\hline ARAS-G & 0.967 & 0.933 & 0.867 & 0.983 & 0.967 & 0.967 & 0.983 & 0.983 & 0.917 & 0.983 & 0.850 & 0.933 \\
\hline VIKOR-G & 0.917 & 0.850 & 0.900 & 0.850 & 0.917 & 0.850 & 0.917 & 0.867 & 0.967 & 0.833 & 0.883 & 0.983 \\
\hline
\end{tabular}

Note: ${ }^{\star}$ Threshold value taken 0.8 . 
As per Table 16, the relationship between all the ranking values of $\left(r_{s}\right)$ for the given 12 sets of criteria weights, are greater than threshold value (here taken 0.8 ), indicating existence of a strong relationship between the ranking results. This confirm the stability and reliability of the ranking result based on COPRAS-G method.

\section{Conclusions}

Telecommunication is a very challenging and ever-changing sector, comprising of various systems playing a vital role towards an economic development of the nation. The proper supplier selection plays a predominant role for efficient operation of this sector' supply chain. The study considers the process of multi-criteria decision-making (MCDM) approach combining Fuzzy Rasch and COPRAS-G to evaluate the suitable supplier among five alternatives for raw material considering ten risk criteria. Rasch in triangular fuzzy interval is used to compute the weight of risk criteria, which are given as input for COPRAS in grey interval (COPRAS-G) for ranking the alternatives. The example of supplier selection in risk-based criteria is used as a case study here to validate the proposed approach.

The MCDM techniques can produce significant results to bridge the gap between the past and present research in Telecommunication sector for supplier selection problem. The proposed method is precise, efficient and convenient to help the decision makers to choose the suitable material among the alternative suppliers. Fuzzy Rasch model is capable of handling imprecise information when determining the weights of risk criteria's. COPRAS-G method allows the uncertain information about the criteria to express in internal and obtain ranking of supplier alternatives. Taking into consideration of the comparative sensitivity analysis of the ranking results performed under different criteria weights, it can be said that the approach has good stability as well consistent with the other compared methods. Moreover, the method is based on opinion of expert, the result of which depend on experience and knowledge of decision makers. For different group of expert, the result will be different. So, proper judgement should be taken on selecting participants who have profound knowledge about this area. This hybrid MCDM method can be applied to other group decision making problem involving other uncertain domains viz. rough number, Z-number, D number and shadowed fuzzy number and further research can be done to evaluate alternatives in other industries. Future research could expand the scope of this proposed method by scrutinising the interrelationships among the criteria using Decision Making Trial and Evaluation Laboratory (DEMATEL) and Analytical Network Process (ANP). 


\section{References}

Aghdaie, M. H.; Hashemkhani Zolfani, S.; Zavadskas, E. K. 2013a. Market segment evaluation and selection based on application of fuzzy AHP and COPRAS-G methods, Journal of Business Economics and Management 14(1): 213-233. https://doi.org/10.3846/16111699.2012.721392

Aghdaie, M. H.; Hashemkhani Zolfani, S.; Zavadskas, E. K. 2013b. Decision making in machine tool selection: an integrated approach with SWARA and COPRAS-G methods, Inzinerine Ekonomika Engineering Economics 24(1): 5-17.

Badri Ahmadi, H.; Hashemi Petrudi, S.; Wang, X. 2016. Integrating sustainability into supplier selection with analytical hierarchy process and improved grey relational analysis: a case of telecom industry, The international Journal of Advanced Manufacturing Technology 90(9-12): 1-15.

Beikkhakhian, Y.; Javanmardi, M.; Karbasian, M.; Khayambashi, B. 2015. The application of ISM model in evaluating agile supplier selection criteria and ranking suppliers using fuzzy TOPSIS-AHP methods, Expert systems with Applications 42: 6224-6236. https://doi.org/10.1016/j.eswa.2015.02.035

Belevdere, S.; Morton, N. 2010. Applying the Rasch analysis in health care is increasing and is applied for variable reasons in mobility instruments, Journal of Clinical Epidemiology 63(12): 1287-1297. https://doi.org/10.1016/j.jclinepi.2010.02.012

Buyukozkan, G.; Cifci, G. 2012. A novel hybrid MCDM approach based on fuzzy DEMATEL, fuzzy ANP and fuzzy TOPSIS to evaluate green suppliers, Expert Systems with Applications 39(3): 30003011.

Chatterjee, K.; Kar, S. 2013a. A hybrid MCDM approach for selection of financial institution in supply chain risk management, in IEEE International conference on Fuzzy Systems (FUZZ IEEE) 2013, 08 October, Hyderabad, India, 1-7.

Chatterjee, K.; Kar, S. 2013b. An Induced Fuzzy Rasch-VIKOR model for Warehouse Location evaluation under Risky Supply chain, in Proceeding of $5^{\text {th }}$ International Conference on Pattern Recognition and Machine Intelligence (PREMI 2013), Kolkata, India, 10-14 December. Lecture notes in computer science 8251: 714-719.

Chatterjee, K.; Kar, S. 2016. Multi-criteria analysis of supply chain risk management using interval valued fuzzy TOPSIS, OPSEARCH 53(3): 474-499. https://doi.org/10.1007/s12597-015-0241-6

Chatterjee, P.; Chatterjee, R. 2012. Supplier evaluation in manufacturing environment using compromise ranking method using grey interval numbers, International Journal of Industrial Engineering Computations 3: 393-402. https://doi.org/10.5267/j.ijiec.2011.12.007

Chen, M.; Tzeng, G. 2004. Combining grey relation and TOPSIS concepts for selecting an expatriate host country, Mathematical and computer modelling 40: 1473-1490.

https://doi.org/10.1016/j.mcm.2005.01.006

Deng, J. 1998. Introduction to grey system theory, The Journal of Grey Theory 1(1): 1-24.

Dou, Y.; Zhu, Q.; Sarkis, J. 2014. Evaluating green supplier development programs with a grey analytical network process-based methodology, European Journal of Operational Research 233(1): 420-431. https://doi.org/10.1016/j.ejor.2013.03.004

Dong, Q.; Cooper, O. 2016. An orders-of-magnitude AHP supply chain risk assessment framework, International Journal of Production Economics 182: 144-156. https://doi.org/10.1016/j.ijpe.2016.08.021

Ecer, F. 2014. A hybrid banking websites quality evaluation model using AHP and COPRAS-G: a Turkey case, Technological and Economic Development of Economy 20(4): 758-782. https://doi.org/10.3846/20294913.2014.915596

Felice, F.; Deldoost, M.; Faizollahi, M.; Petrillo, A. 2015. Performance measurement model for supplier selection based on AHP, International Journal of Engineering Business Management 7(17): 1-13. https://doi.org/10.5772/61702 
Freeman, J.; Chen, T. 2015. Green supplier selection using an AHP-Entropy-TOPSIS framework, Supply chain management 20(3): 327-340. https://doi.org/10.1108/SCM-04-2014-0142

Golmohammadi, D.; Parast, M. 2012. Developing a grey-based decision-making model for supplier selection, International Journal of Production Economics 137: 191-200. https://doi.org/10.1016/j.ijpe.2012.01.025

Hashemi, S.; Karimi, A.; Tavana, M. 2015. An integrated green supplier selection approach with analytic network process and improved Grey relational analysis, International Journal of Production Economics 159: 178-191. https://doi.org/10.1016/j.ijpe.2014.09.027

Hashemkhani Zolfani, S.; Chen, I.; Rezaeiniya, N.; Tamošaitienė, J. 2012. A hybrid MCDM model encompassing AHP and COPRAS-G methods for selecting company supplier in Iran, Technological and Economic Development of Economy 18(3): 529-543.

https://doi.org/10.3846/20294913.2012.709472

Ho, H.; Chiang, H.; Pham, D.; Fann, W.; Nagai, M. 2016. A learning outcomes assessment analysis based on the mathematical modeling of Rasch GSP curve, GSM and MSM, Studies in Engineering and Technology 3(1): 109-123. https://doi.org/10.11114/set.v3i1.1766

Huang, J.; Peng, K. 2011. Using Rasch model and GRA to assess international tourist hotel industry performance, Journal of Grey system 23(3): 299-310.

Huang, J.; Peng, K. 2012. Fuzzy Rasch model in TOPSIS: a new approach for generating fuzzy numbers to assess the competitiveness of the tourism industries in Asian countries, Tourism Management 33: 456-465. https://doi.org/10.1016/j.tourman.2011.05.006

India Risk Survey 2014 (IRS). 2014. Report-FICCI 2014 [online], [cited 06 May 2016]. Available from Internet: http://ficci.in/SEDocument/20276/India-Risk-Survey-2014.pdf

India Risk Survey 2015 (IRS). 2015. Report-FICCI 2015 [online], [cited 06 May 2016]. Available from Internet: http://ficci.in/SEDocument/20328/India-Risk-Survey-2015.pdf

India Risk Survey 2016 (IRS). 2016. Report-FICCI 2016 [online], [cited 06 May 2016]. Available from Internet: http://ficci.in/SEDocument/20348/India-Risk-Survey-2016.pdf

Kar, S.; Chatterjee, K. 2014. Supplier selection under ranking interval type-2 fuzzy sets, in S. Satapathy, B. Biswal, S. Udgata, J. Mandal (Eds.). Proceedings of the 3rd International Conference on Frontiers of Intelligent Computing: Theory and Applications (FICTA) 2014, Volume 327 of the series Advances in Intelligent Systems and computing, 9-17. https://doi.org/10.1007/978-3-319-11933-5_2

Keshavarz Ghorabaee, M.; Amiri, M.; Sadaghiani, J.; Goodarzi, G. 2014. Multiple criteria group decision making for supplier selection based on CORPAS method with interval type-2 fuzzy sets, International Journal of Advanced Manufacturing Technology 75(5): 1115-1130. https://doi.org/10.1007/s00170-014-6142-7

Keshavarz Ghorabaee, M.; Zavadskas, E.; Turskis, A. 2016a. Extended EDAS method for fuzzy multicriteria decision-making: an application to supplier selection, International journal of computers communications \& control 11(3): 358-371. https://doi.org/10.15837/ijccc.2016.3.2557

Keshavarz Ghorabaee, M.; Zavadskas, E.; Turskis, Z.; Antucheviciene, J. 2016b. A new combinative distance-based assessment (CODAS) method for multi-criteria decision-making, Economic computation and economic cybernetics studies and research/Academy of Economic studies 50(3): 25-44 [online], [cited 18 April 2016]. Available from Internet: http://www.ecocyb.ase.ro

Li, S.; Murat, A.; Huang, W. 2009. Selection of contract suppliers under price and demand uncertainty in a dynamic market, European Journal of Operational Research 198(3): 830-847. https://doi.org/10.1016/j.ejor.2008.09.038

Liou, J.; Tamošaitienè, J.; Zavadskas, E.; Tzeng, G. 2015. New hybrid COPRAS-G MADM Model for improving and selecting suppliers in green supply chain management, International Journal of Production Research 54(1): 114-134. https://doi.org/10.1080/00207543.2015.1010747 
Meena, P.; Sarmah, S. 2016. Supplier selection and demand allocation under supply disruption risks, The International Journal of Advanced Manufacturing Technology 83(1): 265-274. https://doi.org/10.1007/s00170-015-7520-5

Mehrjerdi, Y. 2014. Strategic system selection with linguistic preferences and grey information using MCDM, Applied Soft Computing 18: 323-337. https://doi.org/10.1016/j.asoc.2013.09.013

Nguyen, H.; Dawal, S.; Nukman, Y.; Aoyama, H. 2014. A hybrid approach for fuzzy multi-attribute decision making in machine tool selection with consideration of the interactions of attributes, Expert Systems with Applications 41: 3078-3090. https://doi.org/10.1016/j.eswa.2013.10.039

Nurnadiah, Z.; Lazim, A. 2012. A new weight of interval type-2 fuzzy Rasch model, Applied Mathematical Sciences 6(75): 3705-3722.

Ogundile, O. 2013. Fraud analysis in Nigeria's mobile telecommunication industry, International journal of scientific and research publications 3(2): 1-4 [online], [cited 15 April 2016]. Available from Internet: www.ijsrp.org

Onut, S.; Kara, S.; Isik, E. 2009. Long-term supplier selection using a combined fuzzy MCDM approach: a case study for a telecommunication company, Expert Systems with Applications 36(2): 3887-3895. https://doi.org/10.1016/j.eswa.2008.02.045

Oztaysi, B. 2014. A decision model for information technology selection using AHP integrated TOPSISGrey: the case of content management systems, Knowledge-Based Systems 70-C: 44-54. https://doi.org/10.1016/j.knosys.2014.02.010

Pancholi, N.; Bhatt, M. 2016. Multicriteria FMECA based decision-making for aluminium wire process rolling mill through COPRAS-G, Journal of Quality and Reliability Engineering vol. 2016, Article ID 8421916.8 p.

Paul, S. 2015. Supplier selection for managing supply risk in supply chain: a fuzzy approach, The International Journal of Advanced Manufacturing Technology 79(1): 657-664. https://doi.org/10.1007/s00170-015-6867-y

Peng, K.; Huang, J.; Wu, W. 2013. Rasch model in data envelopment analysis: application in the international tourist hotel industry, Journal of Operational Research Society 64: 938-944.

https://doi.org/10.1057/jors.2012.97

Pramod, V.; Banwet, D. 2010. Analytic network process analysis of an Indian Telecommunication service supply chain: a case study, Service Science 2(4): 281-293. https://doi.org/10.1287/serv.2.4.281

Pramod, V.; Banwet, D.; Sharma, P. 2016. Understanding the barriers of service supply chain management: an exploratory case study from Indian telecom industry, OPSEARCH 53(2): 358-374. https://doi.org/10.1007/s12597-015-0234-5

Reza, M.; Moghadam, S.; Afsar, A.; Sohrabi, B. 2008. Inventory Lot-sizing with supplier selection using hybrid intelligent algorithm, Applied soft computing 8: 1523-1529. https://doi.org/10.1016/j.asoc.2007.11.001

Roshandel, J.; Nargesi, S.; Shirkouhi, L. 2013. Evaluating and selecting the supplier in detergent production industry using hierarchical fuzzy TOPSIS, Applied Mathematical Modelling 37: 10170-10181. https://doi.org/10.1016/j.apm.2013.05.043

Shemshadi, A.; Shirazi, H.; Toreihi, M.; Tarokh, M. 2011. A fuzzy VIKOR method for Supplier selection based on entropy measure for objective weighting, Expert Systems with Applications 38(10): 12160-12167. https://doi.org/10.1016/j.eswa.2011.03.027

Tan, K.; Wong, W.; Chung, L. 2016. Information and knowledge leakage in supply chain, Information Systems Frontiers 18(3): 621-638. https://doi.org/10.1007/s10796-015-9553-6

Tavana, M.; Momeni, E.; Rezainiya, N.; Mirhedayatian, S.; Rezaeiniya, H. 2013. A novel hybrid social media platform selection model using fuzzy ANP and COPRAS-G, Expert Systems with Applications 40: 5694-5702. https://doi.org/10.1016/j.eswa.2013.05.015 
Turskis, Z., Zavadskas, E. 2010. A novel method for multiple criteria analysis: Grey additive ratio analysis (ARAS-G) method, INFORMATICA 21(4): 597-610.

Viswanadham, N.; Samvedi, A. 2013. Supplier selection based on supply chain ecosystem, performance and risk criteria, International Journal of Production Research 51(21): 6484-6498. https://doi.org/10.1080/00207543.2013.825056

Yu, S.; Wu, B. 2009. Fuzzy item response model: a new approach to generate membership function to score psychological measurement, Quality and Quantity 43: 381-390. https://doi.org/10.1007/s11135-007-9114-2

Zavadskas, E.; Kaklauskas, A.; Sarka, V. 1994. The new method for multi-criteria complex proportional assessment of projects, Technological and Economic Development of Economy 1(3): 131-139.

Zavadskas, E.; Kaklauskas, A.; Turskis, Z.; Tamošaitienè, J. 2008. Selection of the effective dwelling house walls by applying attributes values determined at intervals, Journal of Civil Engineering and Management 14(2): 85-93. https://doi.org/10.3846/1392-3730.2008.14.3

Zavadskas, E.; Turskis, Z.; Kaklauskas, A.; Tamošaitienè, J. 2009a. Selection of the effective dwelling house walls by applying attributes values determined at intervals, Journal of Civil Engineering and Management 14(2): 85-93. https://doi.org/10.3846/1392-3730.2008.14.3

Zavadskas, E.; Kaklauskas, A.; Turskis, Z.; Tamošaitienè, J. 2009b. Multi-Attribute decision-making model by applying Grey numbers, INFORMATICA 20(2): 305-320.

Zhang, J.; Wu, D.; Olsen, D. 2005. The method of grey related analysis to multiple attribute decisionmaking problems with interval numbers, Mathematical and Computer Modelling 42: 991-998. https://doi.org/10.1016/j.mcm.2005.03.003 